Thursday Oct 082009 03:55 PM JOLE v28n1 280101 JJ

\title{
Assessing the Impact of Eliminating Affirmative Action in Higher Education
}

\author{
Jessica S. Howell, California State University, Sacramento
}

This research examines the determinants of the match between high school seniors and postsecondary institutions in the United States. I model college application decisions as a nonsequential search problem and specify a unified structural model of college application, admission, and matriculation decisions that are all functions of unobservable individual heterogeneity. The results indicate that black and Hispanic representation at all 4-year colleges is predicted to decline modestly-by $2 \%$-if race-neutral college admissions policies are mandated nationwide. However, race-neutral admissions are predicted to decrease minority representation at the most selective 4year institutions by $10 \%$.

\section{Introduction}

Nearly 3 million students graduated from high school in 2006 in the United States and grappled with the decision about whether and where to go to college; approximately $30 \%$ of these students are minorities. The postsecondary opportunities available to these minority graduates are related, in part, to the existence of affirmative action policies at U.S. colleges

This research was supported by a grant from the American Educational Research Association, which receives funds for its "AERA Grants Program" from the National Center for Education Statistics and the Office of Educational Research and Improvement (U.S. Department of Education) and the National Science Foundation under NSF grant REC-9980573. Funding from the University of Virginia College of Arts and Sciences and the Bankard Fund for Political Economy is also gratefully acknowledged. Contact the author at jhowell@csus.edu.

[Journal of Labor Economics, 2010, vol. 28, no. 1]

(C) 2010 by The University of Chicago. All rights reserved. 0734-306X/2010/2801-0002\$10.00

Proof 1 
and universities. Although most selective institutions of higher education actively seek and encourage diversity, for an increasing number of colleges the explicit consideration of race in the allocation of admission and financial aid offers is prohibited. Legal decisions and political initiatives in Texas, California, Washington, and Florida during the latter half of the 1990s indicated a trend toward mandated race-neutral policies at U.S. institutions of higher education. ${ }^{1}$ A pair of rulings by the U.S. Supreme Court in $\mathbf{2 0 0 3}$ provided limited guidance on the role of affirmative action in higher education. ${ }^{2}$ Instead, the Court made a distinction between racesensitive admissions policies that are sufficiently "narrowly tailored" to achieve asserted interests in diversity and those that are not, leaving the door open for future lawsuits and more changes to the policy environment. While the proliferation of lawsuits and political initiatives regarding race in college admissions does not insure that affirmative action will eventually disappear entirely from college campuses, the Supreme Court's irresolute actions and impending changes to the high Court's composition provide ample justification for considering the consequences of such a development.

This research seeks to answer the following question. How would a widespread mandate for race-neutral policies in the U.S. higher education market affect the educational investment decisions of individuals and the admissions policies of postsecondary institutions? In the few states that have already eliminated affirmative action in higher education, the response has been characterized by sharp declines in minority admission rates at the affected institutions. ${ }^{3}$ The subsequent decrease in enrollments by underrepresented minorities continues to receive a great deal of attention in the popular press, as does a shift in minority enrollments from more selective to less selective institutions within tiered systems like the

\footnotetext{
${ }^{1}$ The explicit consideration of race by postsecondary institutions was banned at Texas colleges and universities with the 1996 Hopwood decision. Initiatives prohibiting race-sensitive policies in the public sector were passed by voters in California (Proposition 209, 1996) and Washington (Initiative 200, 1998), and mandated by the governor of Florida (One Florida Initiative, 1999).

${ }^{2}$ The Court ruled against the undergraduate admissions policy at the University of Michigan in Gratz v. Bollinger, et al. and supported the "narrowly tailored" used of race by the University of Michigan law school in Grutter v. Bollinger, et al. The full opinion of the Court in both cases can be read at http://www .supremecourtus.gov/opinions/02pdf/02/516.pdf and http://www .supremecourtus.gov/opinions/02pdf/02-241.pdf, respectively.

${ }^{3}$ See Kain and O'Brien (2003) and Bucks (2004) for a thorough account of the experience in Texas. Additionally, a large amount of data is publicly available through the Office of Institutional Research at the University of Texas-Austin (http://www.utexas.edu/academic/oir/) and through the University of California (http://www.universityofcalifornia.edu/research/welcome.html).
}

Thursday Oct 082009 03:55 PM JOLE v28n1 280101 JJ 
University of California. ${ }^{4}$ Examining changes at Texas and California colleges, however, does not tell us how minority representation in higher education would be affected by a nationwide ban on affirmative action. In order to address this broader potential change in education policy, I specify a model of how individuals make postsecondary application and enrollment decisions and how colleges make admissions decisions. College application decisions are specified as a nonsequential search problem where the theoretical properties of the model are used to make the problem tractable and estimable. All three stages of the matching processapplication, admission, and enrollment-are estimated jointly with unobserved student heterogeneity that influences both student and college decisions. The model and estimation procedure, thus, address the fact that colleges possess more information (via essays and recommendation letters) about applicants than is observable in the data to researchers. Jointly modeling college applications, admissions, and matriculation in this way allows unobservable individual attributes that enter into both individual and college decisions to be correlated. These modeling and estimation innovations distinguish the present study from the model and estimation method employed by Arcidiacono (2005). The benefit of estimating a structural model of these choices is that the resulting parameter estimates are the underlying utility parameters, which are invariant to changes in the policy environment. Thus, I am able to estimate the parameters describing student and university choices using data that were collected while affirmative action policies were being used, but then use those parameter estimates to predict the choices that would emerge in a world without affirmative action in college admissions.

It is important to note that, while affirmative action policies have been legally used by colleges since the landmark 1978 Supreme Court ruling in the Bakke v. Regents of the University of California case, there has been a documented decline since the 1970s in the extent to which institutions actually employ affirmative action in college admissions (Brewer, Eide, and Goldhaber 1999). In order to capture student and college preferences that reflect the current use of affirmative action in higher education, I estimate the parameters of the model using data from the high school graduating class of 1992. The student and college choices observed in the nationally representative National Education Longitudinal Study (NELS) are arguably more similar to the current market for higher education than would be true for earlier cohorts of high school graduates. The use of more recent data is important for uncovering the relevant preference parameters and for lending credibility to policy simulations

${ }^{4}$ Conrad and Sharpe (1996) predicted this sort of trickle-down effect prior to the implementation of race-neutral admissions policies in California.

Thursday Oct 082009 03:55 PM JOLE v28n1 280101 JJ 
that alter the policy environment in which individuals and colleges interact.

When I use the structural model parameter estimates to simulate a ban on affirmative action at all 4-year colleges in the United States, the model predicts very small changes in the number or quality of college applications submitted by blacks and Hispanics. ${ }^{5}$ This result is important in light of the more thorough treatment of college application decisions in this study compared to the literature. The results also indicate that black and Hispanic representation at all 4-year colleges would decline by $2 \%$ when race-neutral college admissions policies are implemented on a national scale, but that minority representation on the most selective college campuses is predicted to decline by $10.2 \%$ following an affirmative action ban. ${ }^{6}$ Finally, when I replace affirmative action with a top $10 \%$ program, intensified recruiting efforts by colleges, or programs to improve the perception or reputation of a college among minority communities, none of these programs is predicted to successfully restore minority representation on the most selective campuses.

\section{Literature Review}

\section{A. Analyses of Individual Behavior}

Revealed preference and random utility studies of postsecondary choice typically compare the utility generated by the various college options available to students. Radner and Miller (1975) is the first empirical application of this type of model to the college choice decision, as well as the first to extend the number of postsecondary alternatives beyond two (college and work) through the use of a multinomial logit model (see McFadden 1978). ${ }^{7}$ Radner and Miller point out a potential flaw in their study and, in doing so, encourage a series of refinements attempting to simultaneously model individual and institutional behaviors. Manski and Wise (1983) is probably the most well known of these refinements.

Manski and Wise (1983) address the application, admission, financial aid, enrollment, and completion stages of the postsecondary choice process, stressing the importance of unobservable characteristics that influ-

\footnotetext{
${ }^{5}$ This result is consistent with Card and Krueger (2004) but contradicts the findings of Long (2004).

${ }^{6}$ Not surprisingly, these figures differ from what has been observed in Texas and California following bans in those states. The Texas and California responses were initially strong as affected students pulled away from those states' institutions and sought a college education elsewhere. With the nationwide ban simulated in this study, students' alternatives in all states are affected by the ban, so their response is muted.

${ }^{7}$ The alternatives in early applications of the multinomial logit model to college choice were not specific institutions but, rather, types of colleges like 2-year, public 4-year, private 4-year colleges, and so on.
}

Thursday Oct 082009 03:55 PM JOLE v28n1 280101 JJ 
ence multiple stages of the matching process. In the chapter by Venti and Wise, the authors estimate a system of equations that combine discrete application and admission choices with a continuous measure of the quality of the college to which individuals apply. The results, based on data from the high school class of 1972, indicate that postsecondary attendance is almost entirely explained by student application choices rather than admission decisions made by colleges. For this reason, the current study develops a more realistic model of student application decision as the choice of a portfolio of colleges. Various subsets of the individual and college choices are estimated jointly by Manski and Wise; however, the full set of decisions made in the matching process are not modeled together. As the authors acknowledge, treating various portions of the twosided matching process as though they are exogenous, when in fact they are determined simultaneously within the decision system, may result in biased parameter estimates.

In a more recent addition to the literature on college choice, Light and Strayer (2002) address the sequential decisions of college attendance and completion using a multinomial probit model. As in Manski and Wise (1983), the postsecondary alternatives that individuals choose from are not specific institutions but rather college "types." Light and Strayer allow individuals to choose from among four different college types, where type categories are defined by the median SAT score of enrolled students. The model allows for correlation between the student/college-type disturbance and demonstrates the importance of allowing for unobserved heterogeneity, particularly across sequential and interrelated decisions like college entry and completion. While Light and Strayer do not model college application by students or admission by colleges, both of which are endogenous choices that constrain the enrollment decision with which their model begins, they demonstrate that postsecondary outcomes (college completion probabilities, in this case) are affected by the closeness of the match between students and colleges on both observable and unobservable characteristics. In particular, minority students are more likely to graduate from college than their white peers when unobserved heterogeneity influences both college attendance and completion, but less likely to complete when attendance and completion are modeled independently.

Card and Krueger (2004) focus on individuals' college application decisions by examining where high school seniors in California and Texas chose to send their SAT scores before and after affirmative action was banned in those states' colleges and universities. Their difference-in-differences methodology reveals no apparent change in the SAT-sending behavior of minorities in either state following the elimination of affirmative action in higher education. This result is interesting because it contradicts much of the anecdotal evidence surrounding the affirmative action debate. The structural model approach employed in the current

Thursday Oct 082009 03:55 PM JOLE v28n1 280101 JJ 
study is meant to complement reduced form analyses like the Card and Krueger study; however, the reduced form analysis in this case has several limitations. First, examining student decisions in only two states misses potentially important general equilibrium effects that would arise with a more widespread ban on affirmative action. As pointed out by Heckman, Lochner, and Taber (1998) in their paper on nationwide changes in college tuition policies, "what is true for policies affecting a small number of individuals need not be true for policies that affect the economy at large." A ban on the use of affirmative action in all U.S. colleges could change admissions probabilities for and potentially the preferences of a broad range of college-bound students. Second, the Card and Krueger approach abstracts from the potential effect of the policy change on admissions outcomes and enrollment choices, which are inherently intertwined with student application behavior and likely to be of ultimate interest. A structural model of application, admission, and enrollment allows the unobservable determinants of these decisions to be correlated across decisions. Finally, this reduced form approach does not permit the examination of other policy changes that are not observable in the data. Such additional policy changes may be unobservable because they are difficult to quantify or measure, such as replacing affirmative action with a policy to improve minority student recruiting and retention, or because they are only proposed changes and not yet enacted. While a unified structural model of college applications, admissions, and enrollment decisions addresses all three of these limitations, the structural approach also has its limitations. In particular, placing structure on these individual and college choices involves more assumptions about underlying behavior than the reduced form approach. In this regard, the structural model and its predictions are valid only if the underlying assumptions are plausible and the model is correctly specified.

Arcidiacono (2005) models each stage of interaction between individuals and colleges, as well as choice of college major and the impact it has on future earnings. Arcidiacono's primary focus is the effect of changes in college admissions and financial aid policies on individuals' future earnings. This emphasis on earnings requires the author to utilize an older data set, the National Longitudinal Study of 1972 (NLS-72), and to place additional structure on the already extensive set of individual and college decisions (i.e., choice of college major, college transfer and retention, earnings, etc.). He finds that removing the race-based advantage in college admission and financial aid does affect the educational outcomes of minority students but has little effect on their future earnings. Because Arcidiacono (2005) is the model that is most similar to the present study, additional differences are illuminated in several places throughout the paper.

Thursday Oct 082009 03:55 PM JOLE v28n1 280101 JJ 


\section{B. Analyses of University Behavior}

The vast majority of 4-year colleges admit nearly all applicants who meet some minimum requirement, such as a high school diploma or GED and perhaps a standardized test. Bowen and Bok (1998) estimate that only about $25 \%$ of all colleges and universities in the United States receive enough applications that they can be selective about whom they admit. "Selective" in this context need not refer to simply the applicants with the highest test scores or grade point averages, however. Colleges with large applicant pools may select on whatever student attributes enter into the college's objective function. The difficult question regarding the behavior of universities is what objective function they seek to maximize.

Research on the supply side of the market for higher education struggles with the fact that most colleges and universities only loosely resemble profit maximizing firms or other nonprofit institutions that charge a price for services rendered (like hospitals). Colleges have enough unique attributes and constraints on their behavior that they are often placed into a category by themselves. With no universally accepted theory of the firm to readily apply when the firms are colleges, a number of studies examine the choices of a single institution as a starting point for understanding college decision making. ${ }^{8}$ These institution-specific studies utilize more detailed data than are available for a nationally representative sample of colleges, and, although the studies are informative, the results are not easily extended to other colleges or a broader scale.

A number of studies attempt to determine which applicant attributes postsecondary institutions appear to prefer, and many of these studies find evidence of a preference for racial minorities in college admissions. In his analysis of High School and Beyond data, Kane (1998) finds evidence of race-based affirmative action at colleges in the top $20 \%$ of the SAT distribution. He estimates the preference given to black applicants to be equivalent to 400 points on the SAT or $\frac{2}{3}$ of a GPA point. Bowen and Bok (1998) also report evidence of a college preference for minorities using the College and Beyond data set. They estimate that black applicants face probabilities of admission to elite schools that are approximately 20 percentage points higher than their white counterparts. According to both Breneman (1994) and Duffy and Goldberg (1998), qualitative evidence of college preferences for minority student enrollments also exists. Both of

\footnotetext{
${ }^{8}$ Miller (1981) examines the supply behavior of elite private universities using data from Stanford University's admissions and financial aid offices. University decision makers maximize institutional welfare subject to a budget constraint by choosing how many of each applicant type to admit and the composition of financial aid packages for each type. Ehrenberg and Sherman (1984) perform a similar analysis for Cornell University, where the university chooses what fraction of students' total college bill to cover rather than the composition of the aid package.
}

Thursday Oct 082009 03:55 PM JOLE v28n1 280101 JJ 
these books cite the stated preferences of liberal arts college officials for racial minorities. None of this literature implies that selective colleges care more about racial diversity than other factors in making their admissions decisions, but it does demonstrate that race is a factor in college admissions. ${ }^{9}$

\section{Econometric Model of Individual Behavior}

At some point prior to high school graduation, an individual collects information about his postsecondary options by talking to family, friends, teachers, and guidance counselors about jobs, vocational schools, community colleges, and/or 4-year colleges. Based on this initial information and his expectations about wages (current and future), probabilities of admission, and financial aid packages, he ranks the alternatives and chooses a portfolio of colleges to apply to that maximizes his expected indirect utility. After submitting applications to this portfolio of schools, he learns additional information about the alternatives, such as the actual admissions and financial aid decisions of the colleges and also how his preferences may have been altered by campus visits, more discussion with family and friends, or other less quantifiable factors. The incorporation of this additional information is followed by a matriculation decision, which may be going to work, attending community college, or enrolling in one of the 4-year colleges to which he is offered admission. As with application decisions, expected utility maximization drives his enrollment choice. An economic model of individuals' postsecondary choices connects this straightforward series of decisions.

High school seniors face $J+2$ postsecondary alternatives, which include the labor force, community college, and $J$ 4-year degree-granting colleges and universities. Let $U_{i j}$ be the indirect utility that individual $i$ derives from choosing to purchase a college education from institution $j$. Utility is a function of observable benefits and costs associated with $j$, which are measured by interactions of individual characteristics and college attributes, $X_{i j}$. Individual characteristics contributing to utility include academic ability, race, family income, and characteristics of the individual's high school. These characteristics are permitted to interact with important attributes of colleges such as the quality and diversity of the student body, tuition, and financial aid generosity. Additional variables in $X_{i j}$ that vary with each potential individual/college pair are distance between $i$ 's high school and college $j$ and how individual $i$ 's academic ability compares to others attending college $j$. An individual's unobserved taste for a college

\footnotetext{
${ }^{9}$ Another demonstrated preference of selective colleges and universities that is actually inversely related to race is for children of alumni. Howell and Turner (2004) examine these "legacy" admissions and the controversy that surrounds this long-standing practice.
}

Thursday Oct 082009 03:55 PM JOLE v28n1 280101 JJ 
education, regardless of the specific institution it comes from, is represented by an individual-specific fixed effect, $\mu_{i}$. The utility $U_{i j}$ also may be influenced by the postsecondary decisions of friends or some other aspect of $i$ 's taste for alternative $j$ that is known only to individual $i$, denoted by $\xi_{i j}$. These two components of utility, $\mu_{i}$ and $\xi_{i j}$, are known to individual $i$ prior to applying or enrolling at any postsecondary institution but are not observed by the econometrician (or colleges) during any stage of the process. For simplicity, I assume that indirect utility is a linear function of observed and unobserved benefits and costs. I also assume that values of a random disturbance term, $\varepsilon_{i j}$, are drawn independently from an extreme value distribution. Individuals observe their values of $\varepsilon$ after they submit applications and before making an enrollment choice. ${ }^{10}$ These assumptions yield an indirect utility function for individual $i$ at college $j$ of the form

$$
U_{i j}=X_{i j} \beta+\mu_{i}+\xi_{i j}+\varepsilon_{i j} .
$$

Because opportunity cost (i.e., forgone income) is the greatest cost associated with college attendance and it is not captured in the $X_{i j}$ variables discussed above, I incorporate this cost into the model by providing individuals with several "outside options," one of which is entering the work force. Any high school senior choosing not to purchase a college education from a 4-year degree-granting institution following graduation is assumed to either enter the labor force, which yields utility $U_{i l f}$, or purchase a postsecondary education from a community college, which generates $U_{i c c}$ for individual $i$. The indirect utility functions are specified similarly to equation (1); $U_{i f f}=X_{i l f} \beta+\xi_{i l f}+\varepsilon_{i l f}$ and $U_{i c c}=X_{i c c} \beta+$ $\xi_{i c c}+\varepsilon_{i c c}$ where $X_{i f}$ and $X_{i c c}$ may include individual attributes and characteristics of individual $i$ 's local labor market. ${ }^{11}$ Individual-specific taste for college, $\mu_{i}$, does not appear in either $U_{i l f}$ or $U_{i c c}$ although both of these outside options include pre- and postapplication errors, $\xi$ and $\varepsilon$. I assume that $\varepsilon_{i l f}$ and $\varepsilon_{i c c}$ are also drawn from the extreme value distribution, independently of the other $\varepsilon_{i j}$, and are unknown to $i$ until after the application stage.

\section{A. Application Decision}

Much like a person hunting for a new apartment or a worker searching for a new job, college-bound individuals often submit applications to

\footnotetext{
${ }^{10}$ One of the benefits of this assumption is that it allows individuals to apply to college and even be offered admission, but still choose to enter the labor market in the enrollment stage of the decision-making process. The assumption also has nice statistical advantages that will be discussed in the next section.

${ }^{11}$ In estimation, I exclude individual attributes from $U_{\text {ilf }}$ and $U_{\text {icc }}$ because they are not separately identified from the parameters on those same individual attributes that do not vary with $j$ that are included in $X_{i j}$ in eq. (1).
}

Thursday Oct 082009 03:55 PM JOLE v28n1 280101 JJ 
several colleges because of the length of time between applying and learning whether or not an application was successful. Therefore, it is reasonable to assume that individuals who elect to apply to college submit multiple applications simultaneously or search nonsequentially. ${ }^{12}$ This means that individuals simultaneously choose how many applications to submit as well as to which postsecondary institutions to apply. Modeling both of these features of the application decision, therefore, requires a method of evaluating sets of colleges that vary in number and composition.

I begin the analysis by defining a set of institutions and its value to individual $i$. Define a $(J \times 1)$ binary vector $a_{i}$ such that $a_{i j}=1$ if and only if individual $i$ applies to the $j$ th college alternative. Individual $i$ 's application strategy is then defined by the set $S_{i a}=\left\{j \mid a_{i j}=1\right\}$, which contains $n_{a}$ elements. To be clear, $S_{i a}$ includes only applications to 4 -year degreegranting institutions because I assume that all individuals have access to the outside options, which do not require an "application" in the same sense that most 4-year colleges do. The value of an application strategy depends upon the expected utility generated by each alternative in $S_{i a}$, the probability of admission at each of these alternatives, and the cost of application. I assume that individual $i$ incurs a fixed cost, $\kappa_{i}$, of applying to any positive number of colleges and a marginal cost for each specific institution $j$ to which he applies, given by $c_{i j}{ }^{13}$

Consider a simple example where individual $i$ applies to a single 4-year institution, State College no. 2 (i.e., $a_{i}=\left(\begin{array}{lllll}0 & 1 & 0 & \ldots & 0\end{array}\right), S_{i a}=\{2\}$, and $\left.n_{a}=1\right)$. This individual has three potential options: he may enter the labor force, enroll in community college, or attend State College no. 2 if offered admission. In calculating the value of this application strategy, the utility that would be generated by each of these options must be weighted by the probability that they are truly options. Denote $P_{i j}$ as the probability that individual $i$ is offered admission to postsecondary alternative $j$ and $E\left[\max _{j}\left\{U_{i j}\right\}\right]$ as the expected value of $U_{i j}$ conditional on $U_{i j}$ being the maximum utility generated by any of the $j \in J$ alternatives to which $i$ is admitted. I assume that the probability of admission is zero at institutions to which individuals do not apply but that individuals can always enter

\footnotetext{
${ }^{12}$ Early action and early decision, which may be thought of as more sequential search methods, dramatically increased in popularity during the latter half of the 1990s. Prior to that, these programs were little-used options for exceptional students who were certain about where they wanted to go. During the sample period I examine (applications in the 1991/92 academic year), colleges were just beginning to respond to declining high school graduation rates with increased reliance on early action/decision programs (Williams 2001; Mahoney 2002). See Avery, Fairbanks, and Zeckhauser (2001) for a more explicit treatment of early decision/ action programs.

${ }^{13}$ Because there are most likely significant economies of scale involved with applying to multiple colleges, costs are specified such that the average cost of applying is diminishing in the number of applications submitted.
}

Thursday Oct 082009 03:55 PM JOLE v28n1 280101 JJ 
the labor force or community college $\left(P_{i l f}=P_{i c c}=1\right)$. I also normalize the marginal costs of applying to community college or the labor force by setting them equal to zero $\left(c_{i l f}=c_{i c c}=0\right)$. The value to individual $i$ of following the application strategy in the current example, $S_{i a}=\{2\}$, is then given by

$$
\begin{aligned}
V\left(S_{i a}\right)= & P_{i 2} E\left[\max \left\{U_{i l f}, U_{i c c}, U_{i 2}\right\}\right] \\
& +\left(1-P_{i 2}\right) E\left[\max \left\{U_{i l f}, U_{i c c}\right\}\right]-\left(\kappa_{i}+c_{i 2}\right) .
\end{aligned}
$$

If $i$ is admitted to College no. 2, he gets the expected utility associated with the greater of the labor force, community college, or College no. 2; if $i$ is not admitted to College no. 2, he gets the expected utility associated with the greater of the labor force and community college alternatives.

When $\varepsilon_{i j}$ is independently drawn from an extreme value distribution with standard deviation parameter $\tau_{\varepsilon}$, I can write

$$
E\left[\max _{j}\left\{U_{i j}\right\}\right]=\tau_{\varepsilon} \ln \left[\sum_{j \in S} \exp \left\{\frac{X_{i j} \beta+\mu_{i}+\xi_{i j}}{\tau_{\varepsilon}}\right],\right.
$$

where $S$ is a subset of alternatives including the labor force, community college, and all 4-year colleges to which individual $i$ applies. ${ }^{14}$ Utilizing this result and defining $\psi_{i j}=\left(X_{i j} \beta+\mu_{i}+\xi_{i j}\right) / \tau_{\varepsilon}$, equation (2) becomes ${ }^{15}$

$$
\begin{aligned}
V\left(S_{i a}\right)= & P_{i 2} \tau_{\varepsilon}\left[\ln \left(\sum_{j=l f, c, 2,2} \exp \left\{\psi_{i j}\right\}\right)\right] \\
& +\left(1-P_{i 2}\right) \tau_{\varepsilon}\left[\ln \left(\sum_{j=l f, c c} \exp \left\{\psi_{i j}\right\}\right)\right]-\left(\kappa_{i}+c_{i 2}\right) .
\end{aligned}
$$

The value of an application portfolio containing $2,3, \ldots, n$ colleges is defined in a similar fashion, although the expressions become increasingly complex as the number of alternatives increases. Since each of the $n_{a}$ colleges in $S_{i a}$ may deny or admit individual $i$, there are $2^{n_{a}}$ different admission outcomes that an individual might encounter. To help summarize outcomes, define the binary matrix, $d_{a}$ such that $d_{a}^{(l, j)}=1(i$ is admitted to college $j$ under admission scenario $l$ ). Each admission scenario, indexed by $l$ below, occurs with different probability and potentially involves a different expected maximum utility. Define $\rho_{l}\left(S_{i a}\right)$ to be the

${ }^{14}$ The standard deviation parameter $\tau_{\varepsilon}$ captures uncertainty about information revealed between the application and enrollment decisions. This helps to explain why an individual with a strong taste for college $j$ (large $X_{i j} \beta$ and/or $\xi_{i j}$ ) and a high probability of admission at $j\left(\operatorname{large} P_{i j}\right)$ would ever apply to multiple colleges.

${ }^{15}$ When $j$ references the labor force $(j=l f)$ or community college $(j=c c)$ alternatives, the definition of $\psi_{i j}$ is slightly different: $\psi_{i l f}=\left(X_{i f f} \beta+\xi_{i f f}\right) / \tau_{\varepsilon}$ and $\psi_{i c c}=\left(X_{i c c} \beta+\xi_{i c c}\right) / \tau_{\varepsilon}$.

Thursday Oct 082009 03:55 PM JOLE v28n1 280101 JJ 
probability that admissions scenario $l$ occurs and $E_{l}\left[\max _{j \in S_{i a}}\left\{U_{i j}\right\}\right]$ as the expected maximum utility under scenario $l$. Thus, a general expression for the value to individual $i$ of having an application portfolio with $n_{a}$ applications to the 4-year colleges in $S_{i a}$ is

$$
\begin{gathered}
V\left(S_{i a}\right)=\sum_{l=1}^{2^{n_{a}}}\left(\rho_{l}\left(S_{i a}\right) E_{l}\left[\max _{j \in S_{i a}}\left\{U_{i j}\right\}\right]\right)-\left(\kappa_{i}+\sum_{j \in S_{i a}} c_{i j}\right), \\
E_{l}\left[\max _{j \in S_{i a}}\left\{U_{i j}\right\}\right]=\tau_{\varepsilon} \ln \left[\exp \left\{\psi_{i l f}\right\}+\exp \left\{\psi_{i c c}\right\}+\sum_{j=1}^{J} d_{a}^{(l, j)} \exp \left\{\psi_{S_{a}(j)}\right\}\right], \\
\rho_{l}\left(S_{i a}\right)=\prod_{j \in S_{i a}}\left[P_{i S_{a}(j)}\right]^{d_{d}^{(l, j)}}\left[1-P_{i S_{a}(j)}\right]^{\left.1-d_{a}^{(l, j)}\right)}
\end{gathered}
$$

where $S_{a}(j)$ denotes the $j$ th element of the application set $S_{i a}{ }^{16}$ Note that taking the product of college admission probabilities indicates that these probabilities are independent of each other given the information available to the individual. I show later that the presence of unobserved heterogeneity in these admission probabilities removes this independence assumption for the econometrician. I assume that individuals are rational and choose the application strategy that maximizes their value function. Thus, the probability of observing a particular application strategy $S_{i a}$, conditional on the characteristics of individual $i$ and the attributes of all postsecondary alternatives, is the probability that $V\left(S_{i a}\right)$ exceeds the value from following any other application strategy available to individual $i$,

$$
\operatorname{Pr}\left(i \text { applies to } S_{i a} \mid X_{i j}\right)=\operatorname{Pr}\left[V\left(S_{i a}\right)>V\left(S_{i b}\right) \forall b \neq a \mid X_{i j}\right] .
$$

The expressions in equations (4) and (5) are useful for deriving first-order conditions that describe an individual's optimal behavior because they permit individual application decisions to be based on the same marginal analysis that underlies other consumption choices in economics. Intuitively, for each college in an individual's observed application set, the marginal value of applying to that college must be positive, while for other colleges that are not in the observed application set, the marginal

\footnotetext{
${ }^{16}$ The value of an application set specified in Arcidiacono (2005) includes an additive "application stage" error that is specific to the application portfolio, rather than each college in the portfolio (e.g., $\xi_{i j}$ in the current model). This choice is presumably made so that an independently and identically distributed (i.i.d.) EV assumption on the portfolio-specific error term yields a multinomial logit expression for the probability of choosing one application strategy from among all possible strategies. Allowing for an institution-specific error in the application stage makes the probability much more complicated, as is seen below, but also involves less restrictive assumptions on individual behavior.
}

Thursday Oct 082009 03:55 PM JOLE v28n1 280101 JJ 
value of applying to each of them must be negative. The consideration of sets of colleges makes it necessary to be able to think in terms of adding or dropping a marginal college from the set and how such a change affects the value of the application set to the individual.

Rewrite equation (5) as $\operatorname{Pr}\left(i\right.$ applies to $\left.S_{i a} \mid X_{i j}\right)=\operatorname{Pr}\left[V\left(S_{i a}\right)-V\left(S_{i b}\right)>\right.$ $\left.0 \quad \forall b \neq a \mid X_{i j}\right]$. The difference $V\left(S_{i a}\right)-V\left(S_{i b}\right)$ only represents the marginal value associated with a college alternative if $a_{i}$ and $b_{i}$ are defined in a particular way. Because there are many potential $b$ vectors that could serve as an alternative college application strategy to $a$ and I am interested in marginal analysis, I start with the simplest case in which the strategy vectors $a$ and $b$ are exactly alike with the exception of a single element. Consider a change in individual i's application behavior with regard to only college $k$. Let the vector $a / k$ be identical to $a$ except for the $k$ th element (e.g., $\left.(a / k)_{k}=1-a_{k}\right)$. Thus, when $a_{k}=1,(a / k)_{k}$ refers to altering the application strategy such that an application to college $k$ is dropped from $S_{i a}$, and when $a_{k}=0,(a / k)_{k}$ indicates that the strategy is altered such that an application to college $k$ is added to $S_{i a}$. The application set and the number of elements it contains when the application strategy is modified in this way are then defined as

$$
\begin{gathered}
S_{i a / k}= \begin{cases}\left\{j \mid j \in S_{i a}, j \neq k\right\} & \text { if } k \in S_{i a} \\
\left\{j \mid j \in S_{i a}\right\} \cup\{k\} & \text { if } k \notin S_{i a}\end{cases} \\
\text { and } \\
n_{a / k}= \begin{cases}n_{a}-1 & \text { if } k \in S_{i a} \\
n_{a}+1 & \text { if } k \notin S_{i a}\end{cases}
\end{gathered}
$$

An individual's net marginal value from changing the application strategy $S_{i a}$ with regard to a single college $k$ is expressed as follows for

$$
\begin{aligned}
& t= \begin{cases}a, & k \in S_{i a} \\
a / k, & k \notin S_{i a}\end{cases} \\
& M V_{a / k}=V\left(S_{i a}\right)-V\left(S_{i a / k}\right)=P_{i k} \sum_{l=1}^{2^{n_{t}}} \rho_{l}\left(S_{t}\right) D\left(E_{l}\left[\max _{j, k}\right]\right)-c_{i k}, \\
& D\left(E_{l}\left[\max _{j, k}\right]\right)=\left\{\begin{array}{l}
E_{l}\left[\max _{j \in S_{a / k}}\left\{U_{i j}, U_{i k}\right\}\right]-E_{l}\left[\max _{j \in S_{a / k}}\left\{U_{i j}\right\}\right], k \in S_{i a} \\
E_{l}\left[\max _{j \in S_{a}}\left\{U_{i j}\right\}\right]-E_{l}\left[\max _{j \in S_{a}}\left\{U_{i j}, U_{i k}\right\}\right], k \notin S_{i a}
\end{array},\right.
\end{aligned}
$$

Thursday Oct 082009 03:55 PM JOLE v28n1 280101 JJ 


$$
\begin{aligned}
E_{l}\left[\max _{j \in S_{t}}\left\{U_{i j}, U_{i k}\right\}\right]= & \tau_{\varepsilon} \ln \left[\exp \left\{\psi_{i f f}\right\}+\exp \left\{\psi_{i c c}\right\}\right. \\
& \left.+\sum_{j=1}^{J} d_{a}^{(l, j)} \exp \left\{\psi_{S_{a}(j)}\right\}+\exp \left\{\psi_{i k}\right\}\right] .
\end{aligned}
$$

q8

The terms $\rho_{l}\left(S_{t}\right)$ and $E_{l}\left[\max \left\{U_{i j}\right\}\right]$ are defined as in equation (4). The first term in equation (7) is the marginal benefit associated with changing college $k$ 's status in the application set, while the second term is the marginal cost associated with such a change. ${ }^{17}$

Equipped with this more concrete definition of the marginal value of a college application, the first-order conditions describing optimal individual behavior are written succinctly as

$$
\begin{array}{cc}
M V_{a / j}>0, & \forall j \in S_{i a} . \\
M V_{a / k}<0, & \forall k \notin S_{i a}
\end{array}
$$

The conditions in equation (8) state that, for each college to which individual $i$ applies $\left(\forall j \in S_{i a}\right)$, it must be the case that the expected marginal benefit from adding that application to his set exceeds the marginal cost of doing so. Similarly, for each college to which individual $i$ does not apply $\left(\forall k \notin S_{i a}\right.$ ), it must be the case the expected marginal benefit from adding an application to that college is exceeded by the marginal cost of doing so.

Given that the number of 4-year postsecondary alternatives in the United States exceeds 1,000 institutions, the number of marginal value calculations and comparisons associated with the first-order conditions in equation (8) is enormous for each individual in the sample. The fact that these comparisons would have to be made for each iteration of the model parameters makes the problem computationally intractable. The theoretical properties of the model imply that many of these value function comparisons can be avoided by eliminating strategies that are dominated. The process of identifying these dominated strategies, along with a practical example, is explained in appendix A. In short, the theoretical results in appendix A transform a search over all possible sets of colleges to a more tractable and sequential search over colleges. Thus, the conditional

\footnotetext{
${ }^{17}$ Several nice properties of the model emerge from the marginal value expression above. It is straightforward to show that the net marginal value of applying to college $k$ is increasing in the utility and probability of admission at $k$, decreasing in the cost of applying to $k$, and decreasing in the utility and probability of admission at other colleges in $S_{i a / k}$. The marginal cost, $c_{i k}$ in eq. (7), is the pecuniary application fee at college $k$. The nonpecuniary cost of applying to college, $\kappa_{i}$, falls out of the marginal value expression because it is a fixed cost that applies to applying to any positive number of institutions.
}

Thursday Oct 082009 03:55 PM JOLE v28n1 280101 JJ 
probability of following application strategy $S_{i a}$ can be written in terms of a significantly smaller number of marginal value terms than would be otherwise possible, ${ }^{18}$

$$
\begin{gathered}
\operatorname{Pr}\left(i \text { applies to } S_{i a} \mid X_{i j}\right)=\operatorname{Pr}\left[M V_{a / j}>0, \quad M V_{a / k}<0\right. \\
\left.\forall j \in S_{i a}, \quad k \notin S_{i a} \mid X_{i j}\right] .
\end{gathered}
$$

\section{B. Enrollment Decision}

An individual's final choice set is determined by both his application strategies and university admissions and financial aid decisions. Define $S_{i a}^{A}$ as the subset of colleges in $S_{i a}$ that offer $i$ admission as well as the labor force and community college alternatives, which are guaranteed. As in the standard random utility framework, individual $i$ chooses the alternative in his choice set, $S_{i a}^{A}$, that yields the greatest utility. Conditional on unobservables $\mu_{i}$ and $\xi_{i j} \forall j \in S_{i a}^{A}$, the enrollment probability takes the multinomial logit form based on the assumption that $\varepsilon_{i j}$ values are independently drawn from an extreme value distribution. ${ }^{19}$ Thus, the conditional probability that individual $i$ chooses postsecondary alternative $m \in S_{i a}^{A}$, conditional on his application set, observables, and unobservables is

$$
\operatorname{Pr}\left(i \text { enrolls at college } m \mid S_{i a}^{A}, X_{i j}, \mu_{i}, \xi_{i j}\right)=\frac{\exp \left\{\psi_{i m}\left(\mu_{i}, \xi_{i m}\right)\right\}}{\sum_{j \in S_{i a}^{A}} \exp \left\{\psi_{i j}\left(\mu_{i}, \xi_{i j}\right)\right\}} .
$$

Recall that an individual's realizations of the extreme value error, $\varepsilon_{i j}$, occur after all application decisions but before the final enrollment choice is made. This error timing is important for several reasons. First, the

${ }^{18}$ This specification is less restrictive of individual application behavior than the assumptions made by Arcidiacono (2005). Because Arcidiacono has to search over sets of colleges, he constrains individuals so that they can consider at most eight colleges in the application stage, and then they must choose any combination of up to three colleges from within those eight. These assumptions limit the number of sets over which he has to search to

$$
\left(\begin{array}{l}
8 \\
1
\end{array}\right)+\left(\begin{array}{l}
8 \\
2
\end{array}\right)+\left(\begin{array}{l}
8 \\
3
\end{array}\right)=92
$$

which is necessary to make his model computationally tractable. The method I employ does not restrict the number or identity of colleges considered by individuals.

${ }^{19}$ The i.i.d. EV assumption on the distribution of $\varepsilon$ typically is associated with a drawback known as the independence of irrelevant alternatives (IIA) property. If the IIA property was a concern in the current model, it would imply that the ratio of any two enrollment probabilities is not sensitive to the attributes of other alternatives in the choice set. This is not true in the current model because unobserved heterogeneity has been added through $\mu_{i}$ and $\xi_{i j}$.

Thursday Oct 082009 03:55 PM JOLE v28n1 280101 JJ 
inclusion of a postapplication stage error is consistent with the way in which choices that I observe in the data may be influenced by information gained by individuals, but unknown to the econometrician, in between stages. For example, of those individuals who applied to at least one 4year college and had at least one admissions offer, $14 \%$ still opted to enter a community college or the work force. These individuals must have learned something in between application and enrollment to sway their decision; otherwise they would never have applied. Without the identifying assumption that realizations of $\varepsilon$ occur after application, the likelihood function contribution would be zero for these observations because there would be no way to explain an individual's decision to apply to college, receive an offer of admission, yet not choose to enroll. A second benefit of the error timing is the tractability gained by having a closed form probability in equation (10) conditional on unobservables. Although the extreme value assumption on the distribution of $\varepsilon$ is essential for generating the multinomial logit form, the fact that the $\varepsilon_{i j}$ 's are not permitted to drive individuals' application behavior is also a necessary assumption. If realizations of $\varepsilon$ occurred before application, then the $\varepsilon_{i j}$ 's associated with the colleges in $i$ 's application set would no longer be i.i.d. in the enrollment stage, which is also a necessary condition for the multinomial logit form. The fact that there exists a timing difference in the realizations of $\xi$ and $\varepsilon$ does not imply that the enrollment decision is independent of the application-stage error vector, $\xi$. It simply means that the stochastic errors associated with the enrollment decision are independent of $\xi .{ }^{20}$ It might be helpful to think of $\xi_{i j}$ as representing information from individual $i$ 's guidance counselor about college $j$ before he applies and $\varepsilon_{i j}$ as additional information gathered through a campus visit to $j$ after applying.

Conditional on observables and unobservables, the joint probability of observing a specific application strategy and matriculation decision given that application strategy yields a complete description of individual behavior. The data necessary for identification of the individual utility function parameters include exogenous individual characteristics in $X_{i j}$ (race, academic ability, parental education and income, etc.), application choices $\left(S_{i a}\right)$, admission outcomes that determine an individual's final choice set $\left(S_{i a}^{A}\right)$, and attributes of the colleges to which individuals apply and enroll (part of both $X_{i j}$ and $P_{i j}$ in the model above). Colleges and universities then take individuals' application and matriculation behavior into consideration when they determine their admissions rules and financial aid allocation.

\footnotetext{
${ }^{20}$ Any correlation between the stochastic portions of the application and enrollment choices would be anticipated and, therefore, captured by $\xi$ rather than $\varepsilon$ according to the Law of Iterated Expectations.
}

Thursday Oct 082009 03:55 PM JOLE v28n1 280101 JJ 


\section{Econometric Model of University Behavior}

Individual institutions in the market for higher education are complex organizations comprising various economic agents who, undoubtedly, have disparate utility functions. One potentially uniting factor for students, professors, administrators, alumni, donors, and legislators is the reputation or prestige of the university with which these agents are affiliated. U.S. News E World Report's (USNWR) annual college rankings are compelling enough that many students and their parents cite the influence of the USNWR statistics in choosing a college and that many college officials openly admit to engaging in a variety of reputation- and statistics-enhancing activities. ${ }^{21}$ Generally speaking, the stronger an institution's reputation, the larger and smarter the applicant pool it faces, the more generous the donations (and, potentially, the state funding) it receives, the higher the quality of students and faculty it is able to attract, the better its reputation, and so the cycle continues. ${ }^{22}$

Colleges are aware that institutional reputation may be particularly important to potential students because a college education is an experience good; it is difficult for individuals to determine the quality of the product prior to purchasing. ${ }^{23}$ Given that a college almost certainly values repeat purchases from current students who reenroll and from "feeder" high schools who routinely encourage their students to apply/enroll, I assume that college decisions regarding undergraduate enrollment are motivated by factors affecting institutional reputation or prestige. ${ }^{24}$ Each college in the model chooses a threshold admission rule that is a function of observable and unobservable applicant characteristics and an unobservable (to the econometrician and applicant) match value. By calculating the expected net marginal benefit from admitting an applicant with a particular set of characteristics, the admission rule determines the subset of applicants that are offered admission.

Let the utility that college $j$ receives from the composition of its student body, $R_{j}$, be an unspecified function of observable and unobservable (to

\footnotetext{
${ }^{21}$ For example, college officials increasingly advertise themselves to peer institutions in an attempt to influence responses on USNWR's Academic Reputation Survey, the most heavily weighted factor in the overall ranking. See any number of recent popular press articles on these topics, such as Mathews (2000) and Argetsinger (2002).

${ }_{22}^{22}$ Monks and Ehrenberg (1999) find that a decrease in a private, elite college's USNWR rankings is associated with higher admissions rates, lower yield rates, and a lower quality entering class.

${ }^{23}$ The industrial organization literature on experience goods indicates that reputation plays a significant role in firm behavior when the possibility of repeat purchases exists. See Kreps and Wilson (1982) and Milgrom and Roberts (1986) for more on signaling product quality through advertising, reputation, and price.

${ }^{24}$ Other research that addresses the prestige motive of colleges includes Garvin (1980), James (1990), and Winston (1997).
}

Thursday Oct 082009 03:55 PM JOLE v28n1 280101 JJ 
the econometrician) student body characteristics, denoted by $Z_{j}$ and $M_{j}$, respectively, and parameters $\alpha_{t}$ describing the relative importance of these characteristics to the institution's utility,

$$
R_{j}=R\left(Z_{j}, M_{j} ; \alpha_{t}\right) .
$$

The parameter vector $\alpha$ does not vary by institution; instead, the parameters are permitted to vary by institution type, $t$. Types are categories of institutions with shared characteristics such as sector (public or private), academic mission, and admissions selectivity.

Most colleges request several items, such as essays and letters of recommendation, that relay additional information about the applicant to admissions officers. Neither the econometrician nor the applicant observe how postsecondary institutions interpret and value these supporting materials, however. Define $m_{i j}$ as college $j$ 's assessment of the supporting materials included in $i$ 's application. Because the attributes captured by $m_{i j}$ may include leadership skills, the ability to overcome personal hardship, volunteer experiences, and/or artistic talent, $m_{i j}$ is best thought of as college $j$ 's beliefs of how well individual $i$ fits in at institution $j$, or the match value between $i$ and $j .^{25}$ While an applicant's own match value is unknown to him, I assume that he knows the distribution of match values and uses this information to gauge his probability of being offered admission. Aggregating values of $m_{i j}$ over all students enrolled at college $j$ yields $M_{j}$ in equation (11).

If I separate out the attributes specific to the $i$ th individual in equation (11) and denote the observed and unobserved qualities of all other individuals by $Q_{j / i}$, equation (11) can be rewritten as

$$
R_{j}=R\left(Z_{i j}, m_{i j}, Q_{j / i} ; \alpha_{t}\right) .
$$

Define $\tilde{R}_{j}$ as the highest level of utility attainable by college $j$ given its expected budget and capacity constraints. Conditional on $\tilde{R}_{j}$ and the characteristics of all other enrollees at $j$, I can determine the minimum $m_{i j}$ that college $j$ would accept in exchange for an admission offer to applicant $i$. This minimum, or reservation, match value is denoted by $m^{r}\left(Z_{i j}, Q_{j / i}, \tilde{R}_{j} ; \alpha_{t}\right)$. It is a function that defines a threshold admissions rule because college $j$ admits $i$ if and only if $m_{i j}>m^{r}\left(Z_{i j}, Q_{j / i}, \tilde{R}_{j} ; \alpha_{t}\right)$ and denies $i$ otherwise. The more valuable applicant $i$ is to college $j$ in terms of his observable characteristics $Z_{i j}$ and their effect on $R_{i}$, the lower the

\footnotetext{
${ }^{25}$ The inclusion of this match value is important when analyzing changes in university policies that force admissions officers to put a larger weight on less quantifiable or nonquantifiable attributes of applicants. University officials in Texas and California, where affirmative action has already been banned for several years, have cited such a change in their policies following the bans in those states in an attempt to maintain the yield rates of minorities.
}

Thursday Oct 082009 03:55 PM JOLE v28n1 280101 JJ 
match value threshold he must clear to gain admission given the characteristics of other individuals.

Define college $j$ 's unobserved propensity to admit applicant $i, A_{i j}^{*}$, as the amount by which $i$ 's match value exceeds the relevant threshold, $A_{i j}^{*}=m_{i j}-m^{r}\left(Z_{i j}, Q_{j / i}, \tilde{R}_{j} ; \alpha_{t}\right)$. The amount $A_{i j}^{*}$ is not observed to the econometrician (or the applicant); instead we observe $A_{i j}=1\left(A_{i j}^{*}>\right.$ $0)=1\left(m_{i j}>m^{r}\left(Z_{i j}, Q_{j / i}, \tilde{R}_{j} ; \alpha_{t}\right)\right)$ and the probability that college $j$ admits applicant $i$ is

$$
\begin{aligned}
\operatorname{Pr}\left(i \text { admitted to } j \mid Z_{i j}\right) & =\operatorname{Pr}\left(m_{i j} \geq m^{r}\left(Z_{i j}, Q_{j / i}, \tilde{R}_{j} ; \alpha_{t}\right) \mid Z_{i j}\right) \\
& =1-F\left(m^{r}\right),
\end{aligned}
$$

where $F$ is the cumulative distribution function of $m$ and the distribution of $m_{i j}$ is assumed to be independent of $Z_{i j}$. Distributional assumptions on $F$ result in either the familiar probit model (assuming $m$ is normally distributed) or logit model (assuming $m$ is logistically distributed). ${ }^{26}$

\section{A. Admissions Decision}

In practice, I allow the reservation match value, $m^{r}$, to be a function of observable student and college characteristics (and their interactions) as well as a function of the unobservable attributes that influence students' decisions, $\mu_{i}$ and $\xi_{i i}$. By allowing these unobservables to influence both individual and college behavior, I account for the fact that admissions officers are privy to the information revealed through student essays and letters of recommendation and that some of this same information drives the application choices of students to begin with. Under these assumptions, college $j$ 's unobserved propensity to admit applicant $i, A_{i j}^{*}$, is defined as $A_{i j}^{*}=Z_{i j} \gamma+\alpha \mu_{i}+\delta \xi_{i j}+m_{i j}$. As mentioned above, I observe the binary admissions outcome $A_{i j}=1\left(A_{i j}^{*}>0\right)$ rather than $A_{i j}^{*}$. Under the assumption that $m$ follows the logistic distribution, the probability that individual

\footnotetext{
${ }^{26}$ It is straightforward to add financial aid to this model of university behavior so that admission and financial aid offers can be estimated jointly (see Howell 2004). Due to the limited data available on financial aid offers, however, I currently estimate only the parameters associated with admission decisions.

A college's decision about whether to admit a particular applicant is a function of that individual's probabilities of admission elsewhere and his probability of enrolling at the institutions offering admission. This implies that each student must forecast the application decisions of all other potential applicants in order to forecast their own admissions probability correctly. The distribution of individuals' value functions, $V(S)$, would allow each individual to evaluate others' probabilities of admissions, thus characterizing what everyone expects everyone else will do with respect to application choices. A complete model would incorporate this equilibrium sorting of students across schools, but this is beyond the scope of the current study.
}

Thursday Oct 082009 03:55 PM JOLE v28n1 280101 JJ 
$i$ is offered admission at college $j$ conditional on $j$ being in his application set, $S_{i a}$, is

$$
\operatorname{Pr}\left(i \text { admitted at } j \mid j \in S_{i a}, Z_{i j}, \mu_{i}, \xi_{i j}\right)=\frac{\exp \left\{Z_{i j} \gamma+\alpha \mu_{i}+\delta \xi_{i j}\right\}}{1+\exp \left\{Z_{i j} \gamma+\alpha \mu_{i}+\delta \xi_{i j}\right\}} .
$$

Similarly, the probability that individual $i$ is denied admission to college $j$ conditional on $j$ being in his application set, $S_{i a}$, is

$$
\operatorname{Pr}\left(i \text { denied at } j \mid j \in S_{i a}, Z_{i j}, \mu_{i}, \xi_{i j}\right)=\frac{1}{1+\exp \left\{Z_{i j} \gamma+\alpha \mu_{i}+\delta \xi_{i j}\right\}} .
$$

These probabilities of admission and denial by college $j$ generate the probability that individual $i$ receives a particular set of admissions outcomes conditional on the colleges in his application set, $S_{i a}$, observables, and unobservables:

$$
\begin{gathered}
\operatorname{Pr}\left(\operatorname{admission} \text { outcomes } \forall j \in S_{i a} \mid S_{i a}, Z_{i j}, \mu_{i}, \xi_{i j}\right) \\
=\prod_{j \in S_{i a}} \frac{\exp a_{i j} A_{i j}\left\{Z_{i j} \gamma+\alpha \mu_{i}+\delta \xi_{i j}\right\}}{1+a_{i j} \exp \left\{Z_{i j} \gamma+\alpha \mu_{i}+\delta \xi_{i j}\right\}},
\end{gathered}
$$

where $a_{i j}=1$ if individual $i$ applies to the $j$ th college alternative and $A_{i j}=1$ if he is offered admission to college $j$. Note that taking the product of admissions probabilities over colleges in $S_{i a}$ does not imply that these decisions are independent from the econometrician's perspective because all admissions probabilities are functions of unobserved student heterogeneity, $\mu_{i}$ and $\xi_{i j}$, which I integrate over in the likelihood function. From the individual's perspective, however, the admission probabilities are independent based on the information available to him. The data necessary for identification of the college admission parameters includes college characteristics that I take as exogenous (i.e., not jointly determined with admission decisions within the structural model) in $Z_{j}$ (geographic location, application fee, tuition, etc.), individuals' application choices $\left(S_{i a}\right)$, observed college admission offers and denials $\left(A_{i j}\right)$, and exogenous attributes of the individuals from whom colleges receive applications $\left(Z_{i j}\right)$.

\section{Data}

The National Education Longitudinal Study of 1988 (NELS; see NCES 1996) consists of a cohort of eighth graders in 1988 who were surveyed through 2000 by the National Center for Education Statistics (NCES, various years). The NCES randomly sampled schools across the country and then randomly sampled students within those schools. I use all students who were seniors during the 1991-92 academic year, which yields a nationally representative sample of 9,844 observations. Available information includes high school GPA, SAT/ACT score, family characteristics

Thursday Oct 082009 03:55 PM JOLE v28n1 280101 JJ 
including income, the number of postsecondary institutions to which each individual applied, the identity of their first and second college choices, the admissions decisions at these colleges, financial aid application and receipt, and the college in which the student enrolled, if any. Locational coordinates for each high school represented in the NELS sample were compiled with the aid of the Geospatial and Statistical Data Center (Geostat) at the University of Virginia. Gathering the geocode data required accessing high school and school district addresses from the Common Core of Data (CCD) database maintained by the NCES. Each sample respondent's high school coordinates are used to calculate distance from each of the 4-year college alternatives.

The individual-level data in NELS are supplemented by data on the supply side of the U.S. higher education market from the Integrated Postsecondary Education Data System (IPEDS). This data set contains information on all postsecondary institutions' affiliation, enrollment, tuition, faculty size and quality, accreditation, admission requirements, and detailed financial information. Although IPEDS is actually a panel data set, only data from 1992 is used for the present study. Electronic data from Barron's Profiles of American Colleges $(1992,1993)$ as well as the paper copy of the annual college guide provide median SAT/ACT scores of enrolled students at all colleges and Barron's selectivity categories. ${ }^{27}$ Locational coordinates for all IPEDS colleges were also obtained with the aid of Geostat.

Combining all of these data sources links the individual micro-level data with the attributes of the postsecondary institutions to which they apply and enroll. Table 1 summarizes the sample of NELS seniors (col. 1) as well as the subsamples of those who apply to (col. 2) and enroll in (col. 3) a 4-year college. The NELS seniors represent roughly 1,000 unique high schools in all 50 states and the District of Columbia. As indicated in the first column of table $1,56 \%$ of seniors apply to at least one 4-year college and $32 \%$ submit applications at multiple 4-year colleges. In the second and third columns of table 1, we see that college applicants and enrollees are more likely than the sample of seniors to be white and female, have fathers with college experience, attend private high schools, submit

\footnotetext{
${ }^{27}$ Barron's classifies colleges into 10 categories with regard to admissions selectivity. In descending order, these categories are Most Competitive, Highly Competitive+, Highly Competitive, Very Competitive+, Very Competitive, Competitive+, Competitive, Less Competitive, Noncompetitive, and Special. I aggregate these 10 categories into four selectivity types as follows: Most Competitive $(1,202)$ category includes the Barron's descriptors Most, Highly+, and Highly Competitive; Very Competitive $(1,066)$ includes Very + and Very Competitive; Somewhat Competitive (947) includes Competitive+ and Competitive; Less/Noncompetitive (846) includes Less and Noncompetitive and Special. Median SAT scores at schools in each category are in parentheses.
}

Thursday Oct 082009 03:55 PM JOLE v28n1 280101 JJ 
Table 1

Summary Statistics of Individual Characteristics

\begin{tabular}{|c|c|c|c|}
\hline & $\begin{array}{c}\text { All Seniors in } \\
1992 \\
(1)\end{array}$ & $\begin{array}{c}\text { Subset of } \\
\text { Applicants* } \\
\text { (2) }\end{array}$ & $\begin{array}{l}\text { Subset of } \\
\text { Enrollees* } \\
\text { (3) }\end{array}$ \\
\hline \multicolumn{4}{|l|}{ Proportion: $\dagger$} \\
\hline Female & .510 & .529 & .533 \\
\hline White & .695 & .698 & .718 \\
\hline Black & .095 & .095 & .090 \\
\hline Hispanic & .119 & .092 & .082 \\
\hline Asian & .082 & .108 & .105 \\
\hline Native American/other & .010 & .007 & .005 \\
\hline \multicolumn{4}{|l|}{ With father's highest degree: } \\
\hline Less than high school diploma & .124 & .077 & .064 \\
\hline High school diploma & .266 & .216 & .198 \\
\hline Some college & .169 & .179 & .185 \\
\hline College or advanced degree & .263 & .383 & .422 \\
\hline \multicolumn{4}{|l|}{ Attending: } \\
\hline Public high school & .875 & .812 & .790 \\
\hline Catholic high school & .069 & .097 & .106 \\
\hline \multicolumn{4}{|l|}{ Non-Catholic private high } \\
\hline school & .057 & .090 & .104 \\
\hline Applying to any 2-year college & .296 & .164 & .035 \\
\hline Applying to any 4-year college & .557 & 1.000 & 1.000 \\
\hline Submitting 1 total application* & .233 & .419 & .364 \\
\hline \multicolumn{4}{|l|}{ Submitting $2-4$ total } \\
\hline applications* & .248 & .445 & .467 \\
\hline \multicolumn{4}{|l|}{ Submitting $5+$ total } \\
\hline applications* & .076 & .136 & .168 \\
\hline Entering the labor force & .329 & .112 & .000 \\
\hline Enrolling in 2 -year college & .246 & .124 & .000 \\
\hline Enrolling in 4-year college & .425 & .764 & 1.000 \\
\hline Average family income (1987\$) & 42,047 & 50,724 & 54,417 \\
\hline \multirow[t]{2}{*}{ Average SAT score } & 841 & 941 & 976 \\
\hline & $(232)$ & $(215)$ & $(202)$ \\
\hline \multirow{2}{*}{ High school GPA } & 2.87 & 3.13 & 3.22 \\
\hline & $(.743)$ & $(.673)$ & $(.640)$ \\
\hline$N$ & 9,844 & 5,480 & 4,185 \\
\hline
\end{tabular}

more college applications, have better academic performance, and come from families with larger incomes.

There are more than 10,000 postsecondary institutions in the United States, 1,407 of which are traditional public or private not-for-profit 4year institutions; the remainder are predominantly community colleges and trade schools. NELS seniors apply to over 2,500 unique postsecondary institutions, although only 1,037 of them are 4-year public or private not-for-profit colleges. Thus, nearly three-quarters of the 1,407 4-year colleges in IPEDS appear in at least one NELS respondent's application portfolio. Figures 1 and 2 indicate that the characteristics of those 4-year

Thursday Oct 082009 03:55 PM JOLE v28n1 280101 JJ 


\section{Number of Four-Year Colleges in IPEDS and NELS \\ by Institutional Control}

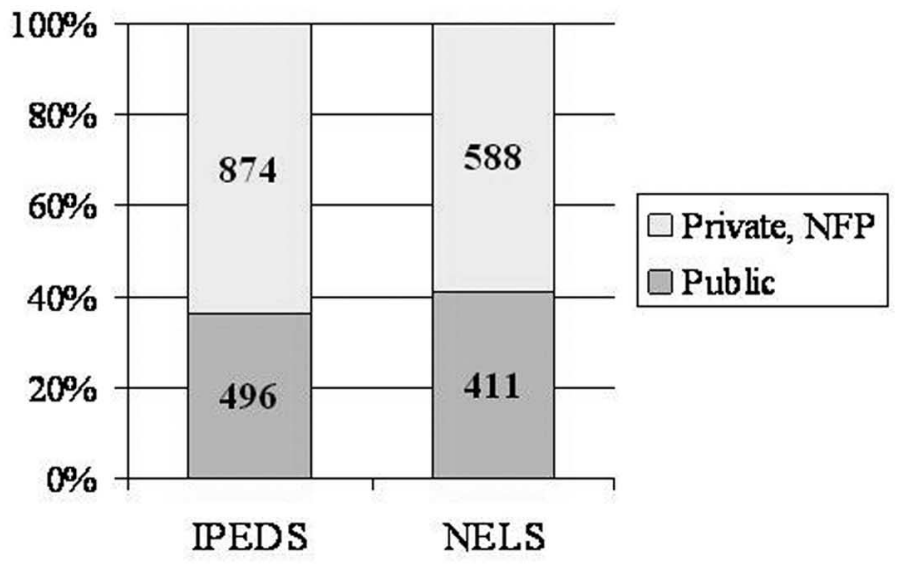

\section{Proportion of Total Fall Enrollment in IPEDS and NELS Colleges by Institutional Control}

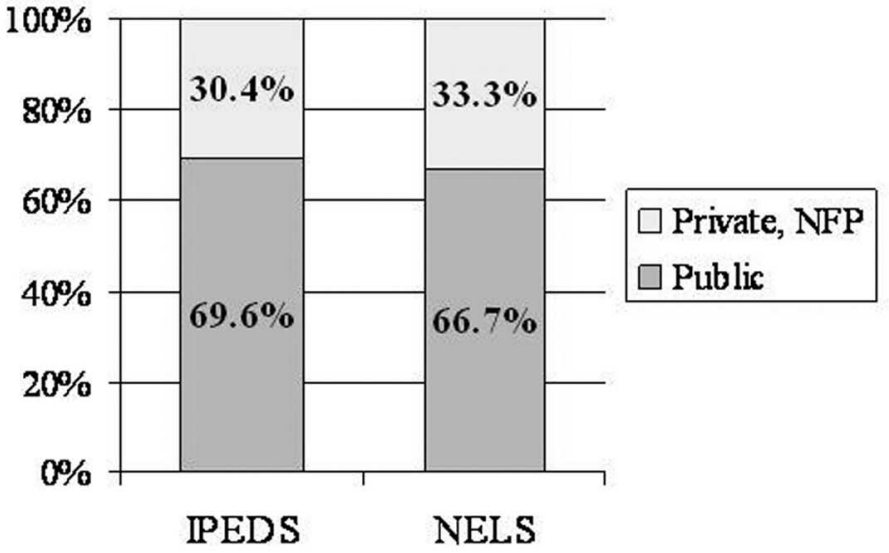

FIG. 1.-Comparison of IPEDS and NELS colleges by institutional control

colleges that are represented in the application and enrollment choices of NELS respondents are comparable to the population characteristics of all 4 -year colleges. For example, the lower panel of figure 1 indicates that $70 \%$ of all U.S. colleges are public institutions while $73 \%$ of the colleges chosen by NELS respondents are public. Thus, the nationally representative sample of students appears to yield a fairly representative sample of colleges.

Thursday Oct 082009 03:55 PM JOLE v28n1 280101 JJ 
Number of Four-Year Colleges in IPEDS and NELS by Institutional Selectivity

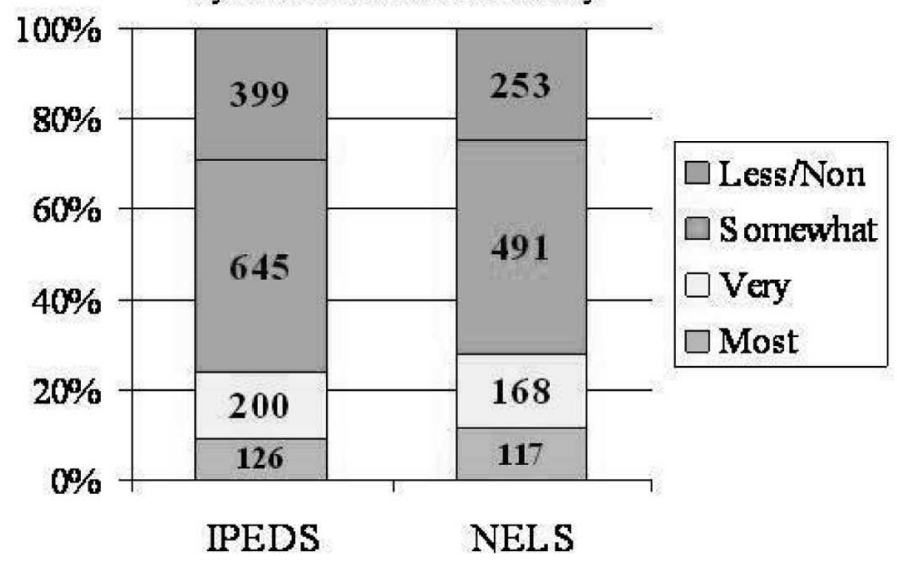

Proportion of Total Fall Enrollment in IPEDS and NELS Colleges by Institutional Selectivity

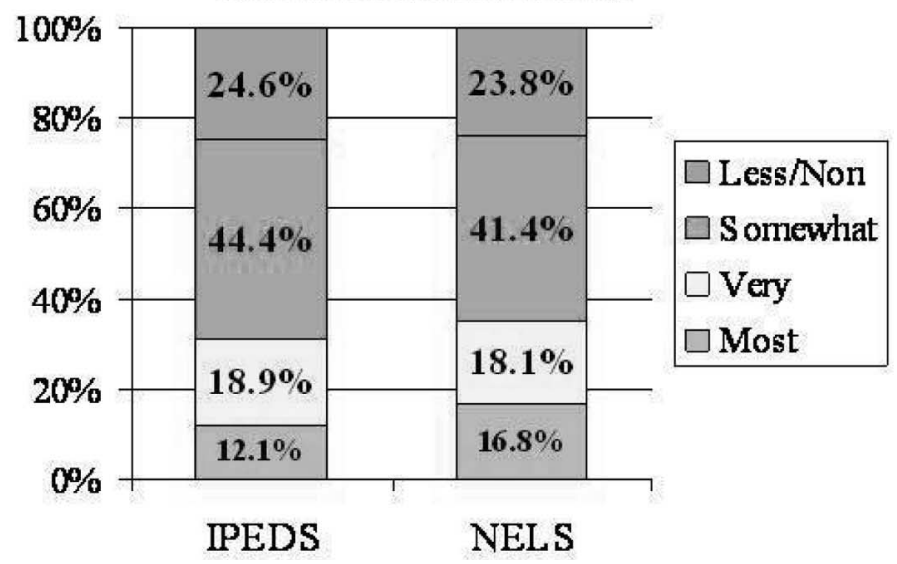

FIG. 2.-Comparison of IPEDS and NELS colleges by institutional selectivity

\section{Preliminary Data Analysis}

In this section, I analyze the relationships between individual and institutional attributes and choices made at various stages of the matching process. Specifically, I separately examine college application choices, admissions decisions, and matriculation choices. These nonstructural analyses are undertaken as preliminary analyses of the data and to guide the specification of the structural model, which allows these decisions to be estimated jointly. The exogenous variation in individual and college char-

Thursday Oct 082009 03:55 PM JOLE v28n1 280101 JJ 
acteristics, when taken along with the available information on application choices, admission decisions, and matriculation choice, serves to identify the parameters in the nonstructural analyses discussed below. This same variation in the data and observed choices also identifies the parameters in the structural model of individual and university decision making. Identification is discussed in more detail in the next section.

Tables 2 and 3 examine the quantity and quality of college applications that NELS respondents submit. In table 2, I present the marginal effect of various individual characteristics on the probability of submitting a particular number of college applications. The marginal effects are based on estimates from an ordered probit model, which are not reported. ${ }^{28}$ The marginal effects in table 2 are interpreted as the change in the probability of submitting the number of applications indicated by the column heading associated with a discrete change in binary variables or a one standard deviation change in continuous variables. For example, the first cell in table 2 indicates that the probability that a male respondent submits zero college applications is 4.9 percentage points larger than a female respondent after controlling for differences in other student characteristics, high school attributes and activities, academic ability, and family characteristics. The ordered probit results imply that black respondents are 15.1 percentage points less likely to submit zero 4-year college applications than their observationally similar white counterparts. ${ }^{29}$ One standard deviation increases in either a student's SAT score or high school GPA have similar (positive) marginal effects on applying to college, although the SAT marginal effects are estimated with more precision. A one standard deviation increase in the proportion enrolled in college preparatory courses in the respondent's high school has an average marginal effect on the number of applications that is roughly twice as large as either the SAT or GPA effect, although the standard errors indicate that these effects are not always statistically different from one another. While the last two rows of table 2 indicate that this model does a fairly good job of predicting the number of college applications students submit, many of the marginal

\footnotetext{
${ }^{28}$ The use of an ordered response model for analyzing the total number of applications is really based on the fact that the variable is interval-coded and the cut-points are known. Thus, the cut-points do not have to be estimated, and the standard deviation parameter need not be normalized to one, as is typically done. I did estimate an interval regression in which the cut-points were treated as data; however, the results were not significantly different from the ordered probit. In fact, the estimated standard deviation parameter was 1.31 , implying that the assumptions made in the ordered probit model are reasonable.

${ }^{29}$ This result is consistent with findings by Manski and Wise (1983). They estimate that black students in 1972 were more than twice as likely as observationally similar white students to apply to a 4-year institution.
}

Thursday Oct 082009 03:55 PM JOLE v28n1 280101 JJ 
Table 2

Determinants of Total Number of College Applications Submitted Using an Ordered Probit Model

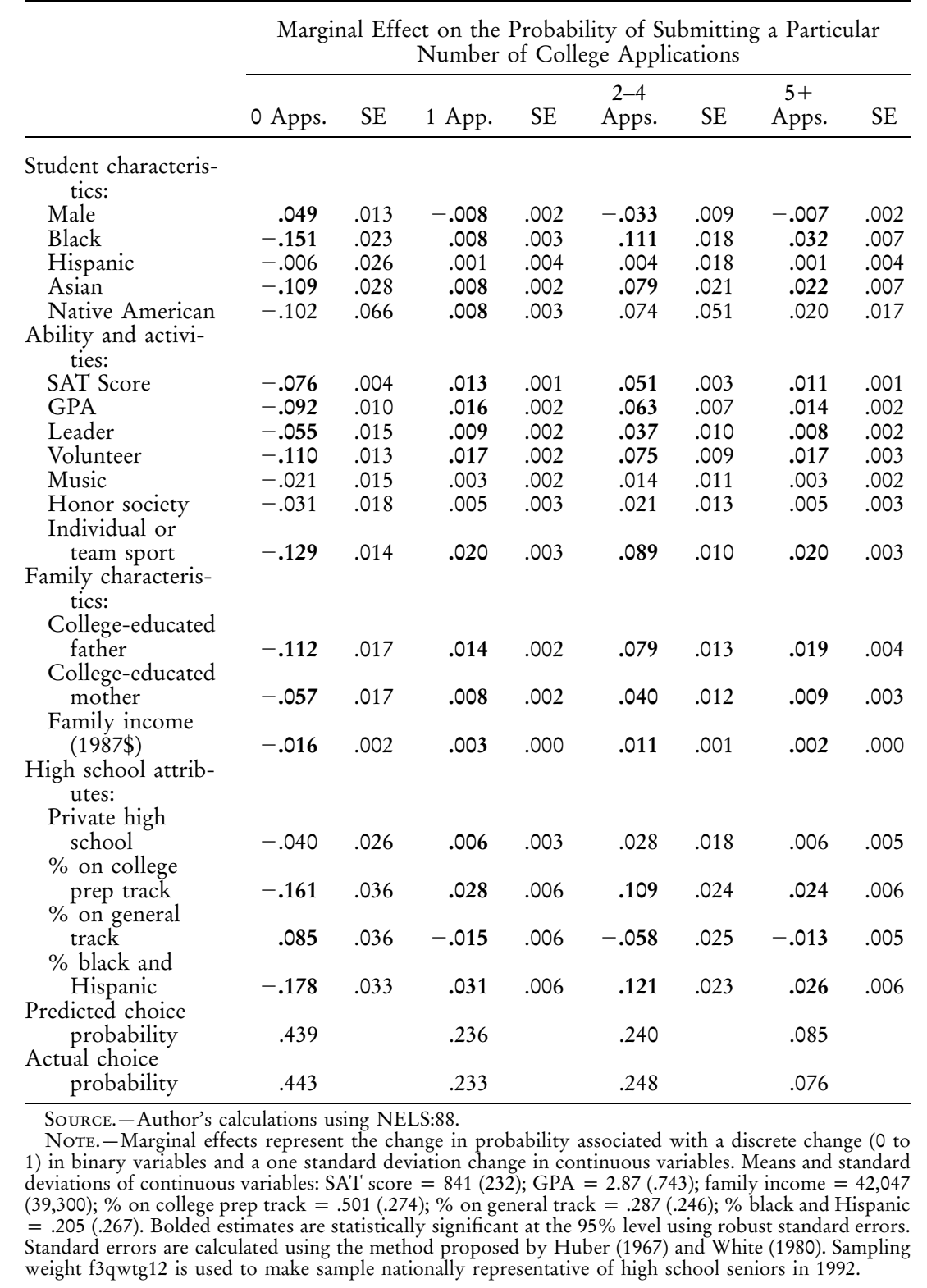

Thursday Oct 082009 03:55 PM JOLE v28n1 280101 JJ 
Table 3

Relationship between College Application Quality and Individual Characteristics

\begin{tabular}{|c|c|c|c|}
\hline & \multicolumn{3}{|c|}{$\begin{array}{c}\text { Dependent Variable Is Median SAT Score at } \\
\text { Colleges in Application Portfolio }\end{array}$} \\
\hline & $\begin{array}{l}\text { Correlation } \\
\text { w/ Median } \\
\text { SAT }\end{array}$ & $\begin{array}{l}\text { Coefficient } \\
\text { Estimates }\end{array}$ & $\begin{array}{l}\text { Standard } \\
\text { Errors }\end{array}$ \\
\hline $\begin{array}{l}\text { Male } \\
\text { Minority } \\
\text { High school GPA } \\
\text { Individual or team sport } \\
\text { Leader } \\
\text { Music } \\
\text { Honor society } \\
\text { Family income } \\
\text { College-educated father } \\
\text { College-educated mother } \\
\text { Private high school } \\
\text { \% black and Hispanic } \\
\text { \% college prep track } \\
\text { Constant }\end{array}$ & $\begin{array}{r}.040 \\
-.166 \\
.323 \\
.074 \\
.107 \\
.018 \\
.247 \\
.303 \\
.299 \\
.255 \\
.238 \\
-.134 \\
.261\end{array}$ & $\begin{array}{r}11.11 \\
-12.91 \\
34.28 \\
.72 \\
-.53 \\
-1.70 \\
40.51 \\
4.34 \\
29.62 \\
10.52 \\
14.53 \\
5.48 \\
47.74 \\
798.39 \\
N=7,752\end{array}$ & $\begin{array}{c}3.31 \\
5.78 \\
2.97 \\
3.43 \\
3.73 \\
4.10 \\
4.29 \\
.60 \\
3.77 \\
4.20 \\
5.18 \\
8.06 \\
6.97 \\
9.69 \\
R^{2}=.23\end{array}$ \\
\hline $\begin{array}{l}\text { Source.-Author's calculat } \\
\text { Note.-Median college SA } \\
\text { utilizing different measures of } \\
\text { and estimates are significant a } \\
\text { sample nationally representati } \\
\text { using the method proposed by } \\
\text { correlated among those applyi }\end{array}$ & $\begin{array}{l}\text { NELS: } 88 \text { and } \\
\text { used as a pro } \\
\text { not significan } \\
\text { level and sam } \\
\text { school seniors } \\
967 \text { ) and Whi } \\
\text { ame college. }\end{array}$ & $\begin{array}{l}\text { or college qua } \\
\text { lter the results } \\
\text { weight f3qwt } \\
\text { 1992. Standard } \\
\text { 980), which all }\end{array}$ & $\begin{array}{l}\text { milar analyse } \\
\text { d correlation } \\
\text { used to mak } \\
\text { are calculate } \\
\text { e errors to b }\end{array}$ \\
\hline
\end{tabular}

effects are not statistically different from one another even though they are statistically different from zero.

Table 3 examines the attributes of the colleges in individuals' portfolios. One attribute of particular interest is selectivity of the college(s) to which a NELS respondent applies, which I proxy with the median SAT score at the college(s) and refer to as application set quality. Table 3 presents pairwise correlations between application set quality and characteristics of the applicant as well as estimated coefficients from a regression of application set quality on those same applicant characteristics. The strong positive correlations between application quality and high school GPA, family income, and parental educational attainment in the first column are not surprising. The regression coefficients in the second column of table 3 are consistent with these correlations but help to quantify the relationships between the variables in terms of median college SAT score. The regression constant indicates that female, nonminority applicants with average characteristics apply to college(s) with a median SAT score of roughly 800 points on average. Being a minority is associated with applying to college(s) with a median SAT score that is 13 points lower, or 787. A one-unit increase in high school GPA has approximately the same

Thursday Oct 082009 03:55 PM JOLE v28n1 280101 JJ 
large, positive effect on the quality of the college(s) applied to as being a member of the honor society, but the largest effect on the quality of colleges applied to appears to be the proportion of an individual's high school taking college preparatory courses. For the average student, a one percentage point increase in the proportion of students on the college prep track is associated with a 48 point increase in application set quality above the mean value of $800 .^{30}$

Next, I address colleges' admissions decisions. Table 4 examines the difference in the probability of admission associated with various individual characteristics. Holding constant all other individual and college attributes, the first column of table 4 shows that black and Hispanic applicants to the most selective colleges are 23 and 9.2 percentage points, respectively, more likely than observationally equivalent white applicants to be offered admission. These marginal effects are consistent with admissions preferences to minorities in Kane (1998), who reports a 17 percentage point estimated effect for blacks and 12 percentage point for Hispanics in the 1982 cohort of high school graduates. The effect of being an underrepresented minority on the probability of admission is statistically insignificant at all but the most selective colleges, a result that is also consistent with the literature. ${ }^{31}$ Another interesting point to note is that applicants to the most selective public colleges face no statistically lower admission probability than at private colleges with similar median SAT scores, but that in-state applicants to the most selective publics enjoy a 13.6 percentage point higher probability of admission. Except for musicians, who enjoy higher probabilities of admission at the most selective institutions, none of the other student high school activities that one might expect to influence admissions, like athletics, are statistically significant. In general, the variables that consistently maintain sign and statistical significance are respondents' SAT score, high school GPA, and family income; however, the marginal effect of each variable is frequently not statistically different across the four admission selectivity categories.

Finally, table 5 examines the relationship between individual characteristics and the postsecondary alternative chosen. The marginal effects presented in table 5 are based on a multinomial logit model that assumes that all high school seniors choose between entering the work force, enrolling in a 2-year college, or enrolling in a 4-year college or university. After controlling for academic ability of the student and his parents, family income, and characteristics of his high school, black seniors are statistically

\footnotetext{
${ }^{30}$ Although high school-level variables like the proportion taking college preparatory classes (and the peer effects that may underlie this result) appear to be important predictors of individual behavior in the preliminary analysis, a more thorough analysis of school and peer effects within the structural model framework is left for future research.

${ }^{31}$ See Kane (1998), Card and Krueger (2004), and Arcidiacono (2005).
}

Thursday Oct 082009 03:55 PM JOLE v28n1 280101 JJ 
Table 4

Determinants of Admission to 4-Year College by College Selectivity

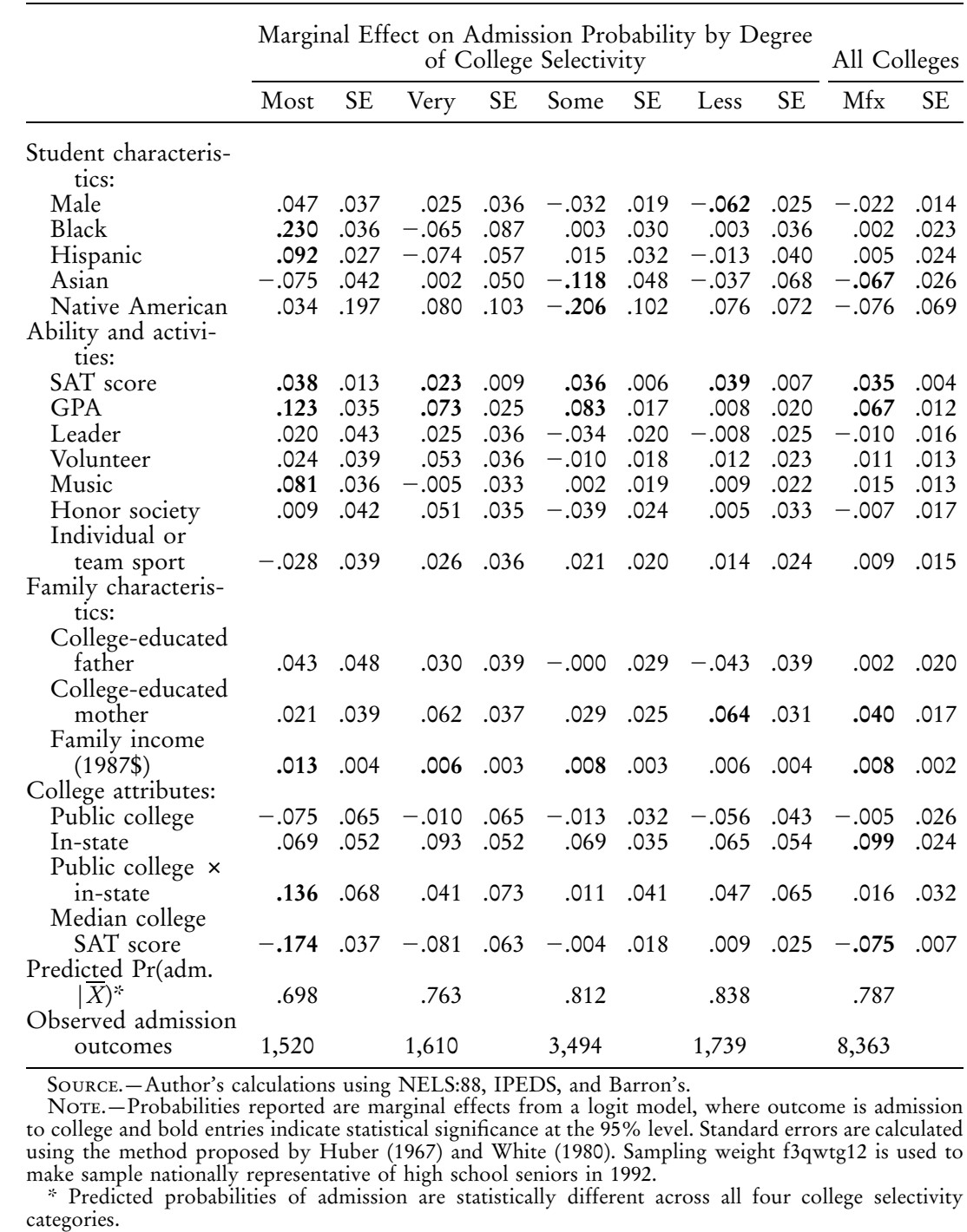

as likely to choose the labor force, 7.8 percentage points less likely to choose a community college, and 12.5 percentage points more likely to choose a 4-year college than their white counterparts. ${ }^{32}$ The characteristics

${ }^{32}$ It should be noted that this model does not control for differences in the quality of 4-year colleges in individuals' choice sets, or for differences in the quality of 2-year colleges or jobs available to individuals for that matter. The

\section{Thursday Oct 082009 03:55 PM JOLE v28n1 280101 JJ}


Table 5

Determinants of Matriculation Choice Using a Multinomial Logit Model

\begin{tabular}{|c|c|c|c|c|c|c|}
\hline & \multicolumn{6}{|c|}{$\begin{array}{c}\text { Marginal Effect on the Probability of Choosing a Particular } \\
\text { Postsecondary Alternative }\end{array}$} \\
\hline & $\begin{array}{l}\text { Labor } \\
\text { Force }\end{array}$ & SE & $\begin{array}{l}\text { 2-Year } \\
\text { College }\end{array}$ & SE & $\begin{array}{l}\text { 4-Year } \\
\text { College }\end{array}$ & SE \\
\hline \multicolumn{7}{|l|}{ Student characteristics: } \\
\hline Male & .055 & .013 & -.026 & .013 & -.029 & .016 \\
\hline Black & -.047 & .026 & -.078 & .023 & .125 & .032 \\
\hline Hispanic & -.013 & .024 & .038 & .025 & -.025 & .030 \\
\hline Asian & -.035 & .035 & .013 & .031 & .022 & .039 \\
\hline Native American & .046 & .063 & -.020 & .069 & -.026 & .074 \\
\hline High school GPA & -.196 & .010 & -.087 & .010 & .284 & .014 \\
\hline \multicolumn{7}{|l|}{$\begin{array}{l}\text { Family and high school } \\
\text { characteristics: }\end{array}$} \\
\hline College-educated father & -.127 & .019 & -.037 & .021 & .163 & .023 \\
\hline College-educated mother & -.089 & .019 & -.023 & .024 & .111 & .024 \\
\hline Family income (1987\$) & -.029 & .004 & .001 & .002 & .028 & .003 \\
\hline Private high school & -.070 & .027 & .002 & .031 & .068 & .033 \\
\hline$\%$ on college prep track & -.182 & .030 & -.052 & .028 & .234 & .034 \\
\hline$\%$ black and Hispanic & -.054 & .033 & .043 & .031 & .010 & .039 \\
\hline \multicolumn{7}{|l|}{ Predicted choice } \\
\hline probability & .327 & & .244 & & .429 & \\
\hline Actual choice probability & .329 & & .246 & & .425 & \\
\hline \multicolumn{7}{|c|}{$\begin{array}{l}\text { SOURCE. - Author's calculations using NELS: } 88 . \\
\text { NoTE. - Marginal effects represent the change in probability associated with a discrete change }(0 \text { to } \\
\text { in binary variables and a one standard deviation change in continuous variables. Means and standard } \\
\text { leviations of continuous variables: GPA }=2.87(.743) \text {; family income }=42,047(39,300) \text {; \% on college } \\
\text { rep track }=.501(.274) ; \% \text { black and Hispanic }=.205(.267) \text {. Bolded estimates are statistically significant } \\
\text { th the } 95 \% \text { level using robust standard errors. Standard errors are calculated using the method proposed } \\
\text { y Huber (1967) and White (1980). Sampling weight f3qwtg12 is used to make sample nationally rep- } \\
\text { esentative of high school seniors in } 1992 \text {. }\end{array}$} \\
\hline
\end{tabular}

associated with the largest marginal effect on the probability of choosing a 4-year college are high school GPA and the proportion of a student's high school taking college preparatory courses. In general, this simple model of postsecondary choice does a good job of predicting the broad choices of individuals following high school graduation.

\section{Structural Estimation and Results}

\section{A. The Likelihood Function}

The first step in specifying an estimable empirical structural model is constructing likelihood contributions for each sample individual. Intuitively, an individual's likelihood contribution is simply the joint probability of observing his choice of application portfolio, his admissions outcomes at those colleges to which he applies, and his particular postsecondary choice conditional on the admissions decisions received. Con-

results are, however, consistent with the findings of Light and Strayer (2002), in which attendance at a college of a particular quality "type" (based on median SAT score) is jointly estimated with college completion.

Thursday Oct 082009 03:55 PM JOLE v28n1 280101 JJ 
ditional on the unobservables $\mu_{i}$ and $\xi_{i j}$, the joint probability in an individual's likelihood contribution, $L_{i}$, is written as separate pieces using conditional probability,

$$
\begin{aligned}
& L_{i}=\operatorname{Pr}(i \text { enrolls at } m \mid \text { admissions outcomes } \\
& \left.\quad \forall j \in S_{i a}, i \text { applies to set } S_{i a}, \mu_{i}, \xi_{i j}\right) \\
& \operatorname{Pr}(\text { admissions outcomes } \\
& \left.\quad \forall j \in S_{i a} \mid i \text { applies to set } S_{i a}, \mu_{i}, \xi_{i j}\right) \\
& \operatorname{Pr}\left(i \text { applies to set } S_{i a}, \mu_{i}, \xi_{i j}\right) .
\end{aligned}
$$

The first piece of $L_{i}$, the conditional probability of enrollment, is already specified in equation (10) as a multinomial logit probability, conditional on unobservables. The second piece of $L_{i}$, the probability of receiving the admissions decisions received at those colleges to which $i$ applies, is already specified in equation (14) as the product of logit probabilities, conditional on unobservables. The third piece of the likelihood function, the probability that individual $i$ follows application strategy $S_{i a}$, is specified in equation (9) in terms of the marginal value associated with applying to each college alternative. Once the likelihood function contributions are computed for each individual in the sample, the natural logarithm of the individual contributions are summed and the resulting function, $\ln L(\theta)=\sum_{i=1}^{N} \ln L_{i}(\theta)$, is maximized through the choice of the parameter vector, $\theta$. The maximum likelihood estimate of $\theta$ are the values of the model parameters that make the choice probabilities and the observed choices of NELS sample members most closely correspond. The challenges associated with estimating this likelihood function as well as the simulation algorithm used to handle unobservables in the model are discussed in appendix B.

\section{B. Identification}

Now that the literature, theory, and preliminary analysis of the data have provided some guidance on the important determinants of application, admissions, and enrollment choices to include in the unified structural model of these choices, I examine how data on choices and other observed variables provide identification of the structural model parameters, $\theta$. I assume that many observable individual and institutional characteristics are exogenous. The data providing exogenous variation include many of the variables in table 1 , such as individuals' gender, race, academic ability (SAT and GPA), and parental education and income. From the perspective of college decision making, several college attributes that I assume colleges take as exogenous (rather than endogenously choose along with their admission rule) include their public/private status, geographic

Thursday Oct 082009 03:55 PM JOLE v28n1 280101 JJ 
location, and the application fee and tuition charged. Variation in these exogenous variables identifies many of the utility function parameters $(\beta$ parameters in eq. [1]). For example, variation in colleges' application fees identifies the application cost parameter in the utility function because there is also variation in the number of college applications individuals choose to submit. Additionally, variation in parental income identifies utility function parameters for the labor force outside option because there is also variation in individuals' decisions about whether or not to go to college. Some of the utility function parameters describe interactions between student and college attributes (e.g., distance between an individual's high school and college). These parameters are identified by variation in the types of colleges to which different types of students apply and enroll (e.g., some students apply/enroll close to home while others choose to apply/enroll far from home, and this variation identifies the utility function parameter on distance). Finally, the parameters describing university preferences $(\gamma$ parameters in eq. [14]) are identified by variation in the exogenous characteristics of individuals who receive those decisions combined with variation in decisions of colleges regarding whom to admit.

Observed application choices, admissions decisions, and enrollment choices vary among observationally equivalent individuals and institutions, which identifies the distributional parameters on unobservables in the model (i.e., mean and standard deviation of $\mu$ and $\xi$ ). For two observationally equivalent individuals who enroll in colleges that are observationally equivalent, differences in the students' application behavior (number of applications and attributes of other colleges in their application sets) identifies differences in the students' unobservable taste for college, $\mu$, as well as differences in their unobservable taste for a particular institution, $\xi$. Likewise, for two observationally equivalent individuals who apply to the same set of colleges, differences in their admissions outcomes identifies the colleges' preferences for applicants' unobservable attributes $(\mu$ and $\xi$ ). Utilizing variation in admissions outcomes to identify unobserved heterogeneity is not new; Dale and Krueger (2002) employ a similar identification strategy in a nonstructural setting to control for selection in estimating the return to college quality.

The identification of the race parameters in the college admission portion of the likelihood function is especially important because the policy experiments conducted below rely on how individuals and universities respond to the elimination of these effects. Identification of these effects comes from assuming that the coefficients on race in college admissions are causal. To address concerns about potential differences in unobserved ability by race, I include multiple observable measures of academic ability, assume that $\mu_{i}$ is independent of race, and assume that there is not some other error term capturing unobserved ability of applicants in the model.

Finally, some identification necessarily occurs through functional form

Thursday Oct 082009 03:55 PM JOLE v28n1 280101 JJ 
and distributional assumptions on error terms. For example, I specify the underlying preferences of individuals and institutions as linear functions of exogenous variables, and I assume that the additive error terms in these equations are independently drawn from extreme value distributions. These are very common assumptions in much of the economics literature and are only made to maintain the model's tractability.

\section{Structural Model Estimates}

Estimates of the structural model parameters are presented in tables 6 and 7. The majority of the parameter estimates are statistically significant and have the anticipated signs. Individual utility is a negative function of tuition, distance between home and college, the cost of applying to college, and the proportion of the college student body that is black or Hispanic, although this last effect is more than offset for black and Hispanic respondents themselves. The estimated effect of family income on the utility from the labor force outside option is negative, which indicates that the labor force is a less appealing alternative the more wealthy is an individual's family. The parameter estimates on the deviation between median SAT of the college alternative and a student's own SAT indicate a nonlinear relationship between the utility associated with a college alternative and the median quality of the student body relative to the individual. Utility from a college alternative first increases as median SAT exceeds the student's own SAT score and then begins to diminish. ${ }^{33}$

The college admissions parameters in the lower half of table 6 are consistent in sign and significance with many of the nonstructural results in table 4. Conditional on individual utility parameters, college admission propensity is an increasing function of student academic ability, athletic participation, family income, and in-state status, and a decreasing function of median college SAT score and selectivity. Minority status has a positive effect on the likelihood of admission and, although this effect is diminishing in a student's SAT score, the positive effect of minority status on admissions is even stronger at the most selective colleges. This is consistent with the common finding in the literature that affirmative action is practiced primarily at those institutions that enjoy sufficient excess demand to be selective in admissions. ${ }^{34}$

Jointly estimating the parameters describing individual and college decisions permits unobserved individual heterogeneity to influence decisions

\footnotetext{
${ }^{33}$ Manski and Wise (1983) estimate that the optimal college quality for an individual is a student body SAT score that is roughly 100 points above the student's own score.

${ }^{34}$ See Kane (1998), Brewer, Eide, and Goldhaber (1999), Card and Krueger (2004), and Arcidiacono (2005), as well as the positive parameter estimates on minority status at only the most selective colleges and universities in table 4.
}

Thursday Oct 082009 03:55 PM JOLE v28n1 280101 JJ 
Table 6

Maximum Simulated Likelihood Estimates of Structural Model Parameters

\begin{tabular}{|c|c|c|}
\hline & Estimate & $\mathrm{SE}$ \\
\hline \multicolumn{3}{|l|}{ Individual utility parameters ( $\beta$ 's): } \\
\hline Percent minority at institution & -.367 & .028 \\
\hline Minority student & -1.505 & 3.069 \\
\hline Minority student $\times$ Percent minority at institution & .451 & .032 \\
\hline Student SAT score & 7.290 & .252 \\
\hline Tuition & -.085 & .005 \\
\hline (Median college SAT - Student SAT score) & 4.790 & .226 \\
\hline (Median college SAT - Student SAT score) ${ }^{2}$ & -.353 & .039 \\
\hline Student SAT score $\times$ Minority student & -1.899 & .356 \\
\hline Distance from student's high school (miles) & $-8.8 \mathrm{E}-04$ & .000 \\
\hline Labor force outside option intercept & 8.011 & .349 \\
\hline Family income in labor force outside option & -1.227 & .073 \\
\hline Application cost & -.248 & .005 \\
\hline \multicolumn{3}{|l|}{ College admission parameters ( $\gamma$ 's): } \\
\hline Male & -.138 & .066 \\
\hline Minority student & 1.111 & .311 \\
\hline High school GPA & .260 & .057 \\
\hline Student SAT score & .184 & .019 \\
\hline Minority student $\times$ Student SAT score & -.113 & .038 \\
\hline Individual or team sport participant & .247 & .065 \\
\hline Family income & .063 & .008 \\
\hline Most selective college & -.515 & .126 \\
\hline Minority student $\times$ Most selective college & 1.059 & .268 \\
\hline Median college SAT & -.217 & .043 \\
\hline Public college & .223 & .114 \\
\hline In-state college & .473 & .106 \\
\hline In-state college $\times$ Public college & .123 & .144 \\
\hline
\end{tabular}

Note. - Bolded estimates are statistically significant at the $95 \%$ level.

on both sides of the higher education market. Table 7 presents estimates of the parameters describing the distributions of unobserved individual heterogeneity. The estimated means and variances of these distributions are used for the policy simulations I conduct, which require drawing values of the unobservables in the model from their estimated distributions. The positive estimated values of $\alpha$ and $\delta$ in table 7 imply that individuals with a stronger unobservable taste for college in general and for a specific 4-year institution have a higher propensity of being offered admission, although the former effect is not statistically significant.

\section{Model Fit}

A simple way of evaluating the quality of the structural parameter estimates is to use them to predict the choices of NELS respondents and compare those predictions to the choices observed in the data. Figure 3 compares actual and predicted application and matriculation choices for black and Hispanic respondents. For example, $34 \%$ of minorities in the NELS data choose to enroll in a 4-year college, while the model predicts this proportion to be $33 \%$. In general, the model does a good job of

Thursday Oct 082009 03:55 PM JOLE v28n1 280101 JJ 
Table 7

Maximum Simulated Likelihood Estimates of Distributional Parameters

\begin{tabular}{lrr}
\hline & Estimate & SE \\
\hline$\sigma_{\xi}:$ Standard deviation of $\xi$ (institution-specific taste) & $\mathbf{9 . 6 5 6}$ & .167 \\
$\mu_{\mu}:$ Mean of $\mu$ (general taste for college) & -49.721 & .389 \\
$\sigma_{\mu}$ : Standard deviation of $\mu$ & .226 & .340 \\
$\tau_{\varepsilon}:$ Standard deviation of $\varepsilon$ & 8.287 & .314 \\
$\alpha$ : Admissions parameter on $\mu$ & .136 & .268 \\
$\delta$ : Admissions parameter on $\xi$ & .044 & .004 \\
\hline Note. The mean of the student/college match parameter $\xi$ is set to zero and not estimated. The \\
standard deviation parameter associated with the $\tau$ distribution is set equal to 10 and not estimated. \\
Bolded estimates are statistically significant at the $95 \%$ level.
\end{tabular}

predicting the matriculation choices of black and Hispanic respondents, on average, and an excellent job of predicting the number of admissions offers but overpredicts college application to some degree. ${ }^{35}$

Although comparisons of actual and predicted choices are helpful in assessing the predictive power of the model on average, a statistical test is necessary to determine whether or not the differences between actual and predicted choices are statistically significant. The $\chi^{2}$ goodness-of-fit test utilized involves computing a test statistic for each of 10 different "events" that individuals choose or realize; applying to $0,1,2-4$, or $5+$ colleges, receiving 0,1 , or $2+$ offers of admission, and choosing the labor force, a 2-year college, or a 4-year college. Define $P_{i t}$ to be the probability that individual $i$ chooses to do event $t$ and $\hat{P}_{i t}$ to be the model's prediction of that probability. For each of the $t$ events, individuals' predicted probabilities are ordered and the sample is divided into quintiles based on these $\hat{P}$ values. If I let $k$ index quintiles, $N_{k}$ be the number of observations falling in quintile $k$, and $N_{k t}$ be the number of individuals falling within quintile $k$ who choose to do event $t$, then the actual and predicted proportion of individuals who choose to do event $t$ in quintile $k$ are, respectively, $P_{k t}=N_{k t} / N_{k}$ and $\hat{P}_{k t}=\left(1 / N_{k}\right) \sum_{i=1}^{N_{k}} \hat{P}_{i t}$. For each of the respondents in the full sample, choices are simulated five times and $\hat{P}_{i t}$ is the average of individual $i$ 's simulated probabilities for event $t$. The test statistic constructed for each quintile, $k$, is $N_{k}\left[\left(P_{k t}-\hat{P}_{k t}\right)^{2} / \hat{P}_{k t}\right]$, which is distributed chi-squared with $k-1$ degrees of freedom when summed over quintiles, $\Sigma_{k=1}^{5} N_{k}\left[\left(P_{k t}-\hat{P}_{k t}\right)^{2} / \hat{P}_{k t}\right] \sim \chi_{k-1}^{2}$.

Table 8 presents goodness-of-fit test statistics for the structural model. The null hypothesis for this statistical test is that the proportions predicted by the model equal the actual proportions in the data; thus, test statistics that fall below the critical value indicate that the model fits the data well. The results indicate that the model does an excellent job of predicting the number of college admission offers received but that it is still missing

${ }^{35}$ The model's overprediction of college application is concentrated among individuals in the lower two SAT score quintiles.

Thursday Oct 082009 03:55 PM JOLE v28n1 280101 JJ 


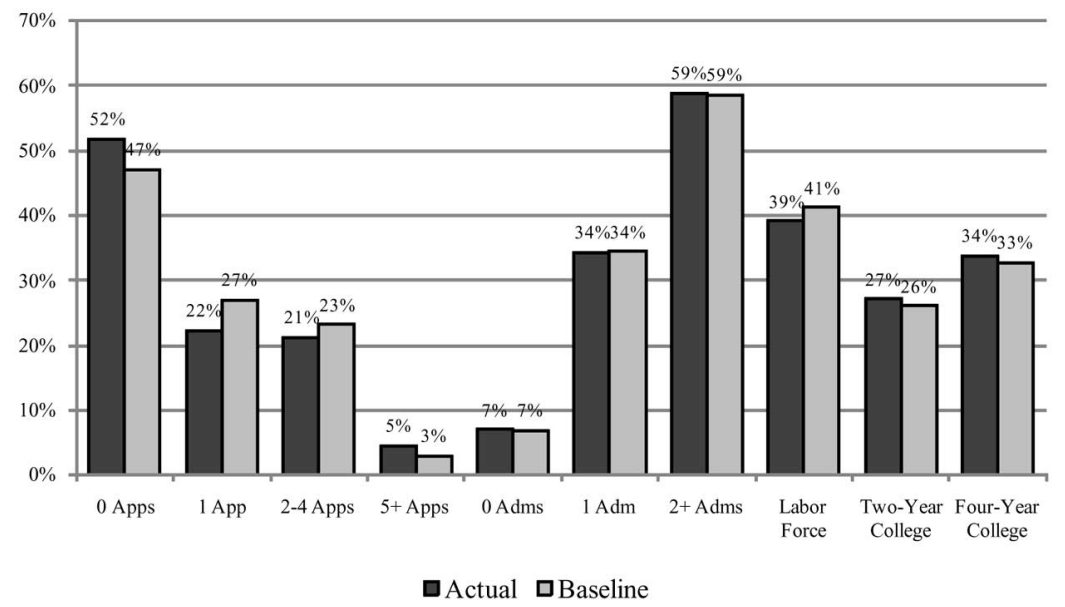

FIG. 3.-Actual versus predicted behavior of black and Hispanic respondents

some aspects of individuals' application behavior and of matriculation decision making. Although figure 3 indicates that the model fits the data quite well on average, the more formal tests by quintile reveal that the model does a particularly poor job of predicting the matriculation choices of those with very low SAT scores despite the inclusion of many SAT variables and interactions. Additionally, the $\chi^{2}$ statistics may be somewhat misleading because the $\hat{P}_{k t}$ in the denominator of the test statistic rewards overprediction relative to underprediction of proportions. Underprediction of college entry is more pronounced among nonminorities, which explains the larger test statistics for nonminorities. While the $\chi^{2}$ statistics for minority matriculation decisions are substantially smaller than for nonminorities, the null hypothesis is still rejected for about half of the events examined. It is quite common for structural models to be rejected when judged by formal statistical tests like the $\chi^{2}$ goodness-of-fit test yet still be deemed useful for counterfactual policy analysis. ${ }^{36}$ In particular, because the simulated changes in policy I conduct in the next section are aimed at minorities and their behavioral responses and because all policy simulations affect admission probabilities, the better model fit for minority individuals and with regard to college admissions is encouraging.

\section{Policy Simulations}

The primary benefit of obtaining estimates of the structural parameters is that they represent the true underlying preferences of the economic

${ }^{36}$ See Hotz and Miller (1993), Gilleskie (1998), Brien, Lillard, and Stern (2006), Keane (2006), and Goeree (2008).

Thursday Oct 082009 03:55 PM JOLE v28n1 280101 JJ 
Table 8 Goodness-of-Fit Specification Tests

\begin{tabular}{lrr}
\hline & \multicolumn{2}{c}{$\chi^{2}$ Statistics } \\
\cline { 2 - 3 } Event & Nonminorities & Minorities \\
\hline Submit 0 applications & $\mathbf{9 . 1}$ & 14.9 \\
Submit 1 application & 83.3 & 21.6 \\
Submit 2-4 applications & 4.9 & $\mathbf{6 . 6}$ \\
Submit 5+ applications & 710.5 & 26.3 \\
Receive 0 admit offers & 3.5 & 4.1 \\
Receive 1 admit offer & $\mathbf{2 . 7}$ & .9 \\
Receive 2+ admit offers & .8 & .1 \\
Enter the labor force & 543.5 & 148.9 \\
Enroll in 2-year college & 802.1 & 304.1 \\
Enroll in 4-year college & $1,194.2$ & 160.6 \\
\hline Note. -The critical value with four degrees of freedom is 13.28. Test statistics
\end{tabular}

in bold indicate the model fits the data well.

agents if the model is correctly specified. These parameter estimates are invariant to changes in the policy environment and, as a result, allow researchers to examine interesting counterfactual public policy questions that most nonstructural methods are unable to address adequately. ${ }^{37}$ The parameter estimates in tables 6 and 7, and the predicted behavior they imply, serve as a baseline against which simulated behavior in new policy environments is compared. The difference between these baseline choices and predicted choices following a change in policy is the estimated effect

\footnotetext{
${ }^{37}$ Consider the following example of the difference between structural and nonstructural parameters in the context of the current research question. Consider estimating students' enrollment choices, independently of application and admission decisions, with a multinomial logit model. If one of the relevant explanatory variables in this logit is the interaction Minority M $_{i} \times$ Minority $_{j}$, the logit coefficient on this explanatory variable indicates how a minority student $\left(\right.$ Minority $_{i}$ ) is more or less likely to enroll in a particular college based on the proportion of the student body at college $j$ that is minority (\% Minority $)$. Most approaches would assume that this coefficient is useful for predicting how a minority student would alter his enrollment choice if \% Minority ${ }_{j}$ changed. Thus, if an affirmative action ban reduces minority representation at college $j$, the coefficient on the interaction term would be used to predict how a minority student would change his enrollment choices in response. This analysis is flawed because such a change in the policy environment might also change a minority student's application choices and their admissions outcomes, which both determine the set from which their enrollment choice is made. In short, the multinomial logit coefficient described above does not fully capture how minority students value college diversity in their utility function, but it is precisely this utility function parameter that is needed to make accurate policy predictions. The structural model presented in this study includes the interaction term Minority $_{i} \times \%$ Minority $_{j}$ in the utility function and, thus, uncovers a parameter that does indicate how minority students value racial diversity when making application and enrollment decisions, as well as how their minority status influences the admission outcomes they realize.
}

Thursday Oct 082009 03:55 PM JOLE v28n1 280101 JJ 
Table 9

Predicted Behavior and Induced Changes of Black and Hispanic Respondents Following Various Simulated Policy Changes

\begin{tabular}{|c|c|c|c|c|c|}
\hline & \multirow[b]{2}{*}{$\begin{array}{c}\text { Baseline } \\
\text { Simulation } \\
(1)\end{array}$} & \multicolumn{4}{|c|}{ Policy Simulations } \\
\hline & & $\underset{(2)}{\mathrm{AA} B a n}$ & $\begin{array}{c}\text { Top } 10 \% \\
\text { Program } \\
(3)\end{array}$ & $\begin{array}{l}\text { Minority } \\
\text { Recruiting } \\
\text { (4) }\end{array}$ & $\begin{array}{c}\text { Minority } \\
\text { Support } \\
(5)\end{array}$ \\
\hline \multicolumn{6}{|l|}{ Proportion choosing to: } \\
\hline Submit 0 applications & .4702 & .4716 & .4714 & .4685 & .4595 \\
\hline Submit 1 application & .2690 & .2683 & .2684 & .2701 & .2751 \\
\hline Submit $2-4$ applications & .2321 & .2315 & .2316 & .2327 & .2364 \\
\hline Submit $5+$ applications & .0286 & .0286 & .0286 & .0287 & .0289 \\
\hline Receive 0 admit offers & .0695 & .0878 & .0877 & .0446 & .0741 \\
\hline Receive 1 admit offer & .3440 & .3510 & .3510 & .3543 & .4080 \\
\hline Receive $2+$ admit offers & .5865 & .5611 & .5613 & .6011 & .5179 \\
\hline Enter the labor force & .4119 & .4154 & .4154 & .4048 & .4187 \\
\hline Enroll in 2-year college & .2608 & .2635 & .2635 & .2569 & .2663 \\
\hline Enroll in 4-year college & .3273 & .3211 & .3210 & .3383 & .3150 \\
\hline \multicolumn{6}{|l|}{ Enroll in most selective } \\
\hline 4-year college & .0304 & .0273 & .0275 & .0291 & .0281 \\
\hline \multicolumn{6}{|l|}{$\begin{array}{l}\text { Proportion induced to: } \\
\quad \text { Submit more }\end{array}$} \\
\hline applications & & .0299 & .0299 & .0245 & .0989 \\
\hline \multicolumn{6}{|l|}{ Submit fewer } \\
\hline applications & & .0209 & .0213 & .0894 & .1806 \\
\hline \multicolumn{6}{|l|}{ Submit same number of } \\
\hline \multirow{2}{*}{\multicolumn{6}{|c|}{ Apply to: }} \\
\hline $\begin{array}{l}\text { Apply to: } \\
\text { More selective colleges }\end{array}$ & & & & & \\
\hline Less selective colleges & & .0426 & .0431 & .0685 & .2432 \\
\hline Same selectivity & & .9165 & .9156 & .8584 & .5023 \\
\hline
\end{tabular}

NotE. - Predicted proportions are based on approximately 50,000 simulations.

of the policy change. The estimated effects of four policy changes are examined in table 9 .

\section{A. Affirmative Action Ban}

The first counterfactual experiment examines how the match between students and postsecondary institutions changes when colleges and universities are prevented from explicitly considering an applicant's race in the college admission decision. ${ }^{38}$ Both the nonstructural and structural results indicate that affirmative action has a positive and statistically significant effect on minority admissions probabilities, particularly at the most selective 4-year institutions, so an affirmative action ban is likely to have the largest effects on minority applicants at a relatively small subset of selective 4-year colleges. There may, however, also be some trickledown effect on minority applicants at moderately and less-selective institutions if minority applicants to the most selective institutions are in-

${ }^{38}$ The affirmative action ban is simulated by eliminating both the main race effects and all differential (by race) slope coefficients in the admission parameters.

Thursday Oct 082009 03:55 PM JOLE v28n1 280101 JJ 
duced to change their application behavior substantially. The baseline predictions of the model along with predicted behavior following an affirmative action ban are presented in the first two columns of table 9.

The results in the top panel of table 9 indicate that a simulated affirmative action ban results in a slightly smaller proportion of minorities applying to 4-year colleges, relative to behavior in the baseline prediction of the model. The lower panel of table 9, which examines in more depth the ways in which blacks and Hispanics are induced by the policy change to alter their college application choices, indicates that approximately $95 \%$ of minorities submit the same number of college applications before and after the ban and $92 \%$ apply to colleges of the same level of selectivity as they did before the ban. Following an affirmative action ban minorities face slightly lower probabilities of admission at those colleges to which they apply (relative to in the baseline), but this has little effect on the average selectivity (as proxied by median SAT score) of the institutions in their application sets, admissions sets, and matriculation choices. Although it makes intuitive sense that some individuals might respond to a ban by submitting more applications or applying to less selective institutions, a small number are also predicted to apply to fewer or more selective institutions. These individuals' baseline application choices are primarily to less and nonselective colleges, so their admission probabilities at colleges in the next selectivity tier are essentially unaffected by the ban, which has its largest effects at the most selective institutions. Generally, predicted changes in application behavior following an affirmative action ban are very small, which is consistent with the Card and Krueger (2004) finding that application choices by black and Hispanic students were minimally affected by the elimination of affirmative action in California and Texas.

Table 9 also indicates that the number of admission offers received by minorities following an affirmative action ban is predicted to fall; the proportion who are predicted to receive multiple admission offers falls by 2.5 percentage points, and the proportion predicted to receive zero admission offers rises by 1.8 percentage points. As a result, postban enrollment at 4-year colleges is predicted to drop by 0.6 percentage points (or $2 \%$ ), a result that is consistent with the $1.9 \%$ drop predicted by Arcidiacono (2005). This result is magnified at the most selective 4-year colleges, where the affirmative action ban is predicted to result in reduced minority representation by $10.2 \% .^{39}$

${ }^{39}$ Arcidiacono (2005) predicts that black student representation at the most selective colleges falls by $45 \%$ when affirmative action is banned from college admissions. This substantially larger negative effect may be reflective of the older cohort examined in that paper (the high school class of 1972), which would have been exposed to stronger college affirmative action policies than in 1992 (the

Thursday Oct 082009 03:55 PM JOLE v28n1 280101 JJ 


\section{B. Potential Replacements for Affirmative Action}

Most colleges and universities that have already been required to abandon race-conscious admissions policies have experimented with potential replacements for affirmative action. I combine the affirmative action ban simulations from the previous section with several of the most popular replacement policies utilized by colleges in Texas, California, and Florida. ${ }^{40}$

\section{A Top $10 \%$ Program}

The first replacement policy considered is a program that guarantees, for a certain percentage of the top graduates from each high school in the state, admission to at least one public state university. These percentage rules, called $x \%$ programs or class-rank rules, were instituted in state public colleges in Texas and Florida following the elimination of affirmative action, where the percentage of top seniors granted admission ranged from $4 \%$ to $20 \%{ }^{41}$ I simulate a top $10 \%$ program by setting admissions probabilities equal to one for all in-state students graduating in the top decile of their high school class at public colleges in their home state. ${ }^{42}$ The predicted behavior of minorities following a simulated affirmative action ban and top $10 \%$ program are presented in the third column of table 9 .

The results indicate negligible changes in application and matriculation behavior relative to the simulated affirmative action ban alone (table 9, col. 2). One explanation for this is that the minorities who were the most likely to be affected by the affirmative action ban (i.e., those applying to the more selective colleges) are quite likely to be in the top $10 \%$ of their high school class, so that this policy has little impact on their admissions

NELS cohort), according to Brewer et al. (1999), and therefore responded more sharply to the removal of those policies.

${ }^{40}$ It should be noted that all of the policy experiments that are coupled with a simulated affirmative action ban could be examined as policy changes on their own. Several states that were not affected by recent court rulings or voter initiatives have implemented or considered $x \%$ programs, for example.

${ }^{41}$ California's $x \%$ program has been in existence since the Master Plan was first conceived in 1960 , and currently the top $12.5 \%$ of graduating high school seniors in the state are guaranteed a spot at one of the University of California campuses. No additional changes to the policy were implemented in California following Proposition 209, which eliminated the use of affirmative action in college admissions.

${ }^{42}$ There are various permutations of these class-rank rules beyond the choice of percentage to offer the guarantee. In Texas, the guarantee is admission to the students' choice of any of the public colleges in the state, while in California the guarantee of admission is to at least one public institution. The simulation that I conduct here is more similar to the Texas policy.

Thursday Oct 082009 03:55 PM JOLE v28n1 280101 JJ 
probabilities. ${ }^{43}$ Additionally, I assume that college enrollments are held constant during the policy simulations. In the real world, however, colleges and universities might expand to accommodate additional students under this sort of policy, which would potentially result in larger effects. In fact, Bucks (2004) points out that selective Texas universities increased total undergraduate enrollment by $10 \%-20 \%$ following the elimination of affirmative action such that the number of minorities enrolled at those institutions remained relatively constant even as their proportional representation decreased.

\section{Increased Minority Student Recruiting}

A second replacement policy considered reflects colleges' attempts to attract more minority applicants through intensified recruitment efforts. Multiple admissions offices in states that have banned affirmative action report this type of response to the ban in an attempt to maintain campus diversity without breaking the law. I assume that minority students face less uncertainty about their admission chances at those colleges actively recruiting them. In practice, conveying additional information about admission probabilities through recruiting is simulated as a decrease in the standard deviation of the distribution of match values between minority students and colleges in the same state. I assume that the standard deviation of unobserved match values is half of its original value. Tightening this distribution increases conditional probabilities of admission for those students who are already relatively more appealing to colleges based on observable characteristics and lowers conditional probabilities of admission for those with less desirable observable characteristics.

The fourth column of table 9 summarizes the effect of an affirmative action ban when it is replaced with intensified recruitment of minorities. Very little change in application behavior relative to the baseline is evident in the top panel of the table, but the bottom panel indicates more induced changes than under either the ban alone or the ban coupled with a top $10 \%$ program. Depending upon whether the policy change increases or decreases an individual's conditional admission probabilities, individuals' application choices change accordingly (i.e., those with higher admission probabilities generally choose to submit fewer applications and/or apply to more selective colleges and vice versa). After new application choices are simulated, the average probability of admission at colleges in these application sets is 10 percentage points higher with intensified recruiting than under an affirmative action ban alone, which leads to fewer applications to more selective colleges on net, increases in the number of admission offers received, and more 4-year college enrollment. Despite a

\footnotetext{
${ }^{43}$ Tienda et al. (2003) espouse this theory in their study of the "10 Percent Plan" in Texas.
}

Thursday Oct 082009 03:55 PM JOLE v28n1 280101 JJ 
1.1 percentage point increase in total 4-year college enrollment over baseline behavior and a 1.7 percentage point increase over the affirmative action ban alone, recruiting is not predicted to restore preban minority representation at the most selective 4 -year institutions.

\section{Increased Minority Student Support}

A final policy experiment is motivated by the notion that college campuses with race-neutral admissions policies may be perceived as inhospitable environments by minority students. Colleges that wish to improve their reputation in minority communities may choose to invest in activities that diminish this perception of the campus. Establishing college preparatory programs in those communities and creating campus organizations that are geared toward the preferences and needs of traditionally underrepresented groups are ways of providing minorities with more support and potentially improving minority perceptions. I allow these perceptions to be shaped prior to the application stage of individual decision making by simulating the increase in minority student support as a one standard deviation increase in the unobservable portion of a student's indirect utility $\left(\xi_{i j}\right)$ associated with each in-state college. Because values of $\xi$ are known before application decisions are made, an increase in $\xi$ may shape perceptions such that application choices are affected. Recall that $\xi_{i j}$ enters directly into $U_{i j}$ and $\xi_{i j}$ also positively affects college $j$ 's admission propensity through the positively estimated parameter $\delta$. Thus, participation in a precollegiate program sponsored by college $j$ or awareness of good student services for minorities at college $j$ positively affects individual $i$ 's affinity for and likelihood of admission to college $j$ prior to applying.

The last column of table 9 summarizes the effect of coupling an affirmative action ban with more support programs for minority students. Although the top panel of the table indicates a decrease in the proportion of minorities who fail to apply to college at all, the bottom panel shows a net decrease in the number of applications submitted. The lower panel of table 9 also indicates that this policy change induces more application shifting by minorities than the other simulations, both in terms of the number of college applications and the selectivity of the colleges to which individuals apply. Because the change in $\xi$ affects both indirect utility and admissions probabilities - the two components of the value functions that determine application behavior-increased minority student support elicits the biggest changes to individuals' value functions and, thereby, predicted application choices. ${ }^{44}$ These changes in simulated application be-

${ }^{44}$ Additionally, some of the changes in application behavior appear to be driven by the fact that this policy change affects utility from and admission probabilities to in-state college alternatives and there is considerable variation in the number and quality of in-state colleges available to individuals who reside in different

Thursday Oct 082009 03:55 PM JOLE v28n1 280101 JJ 


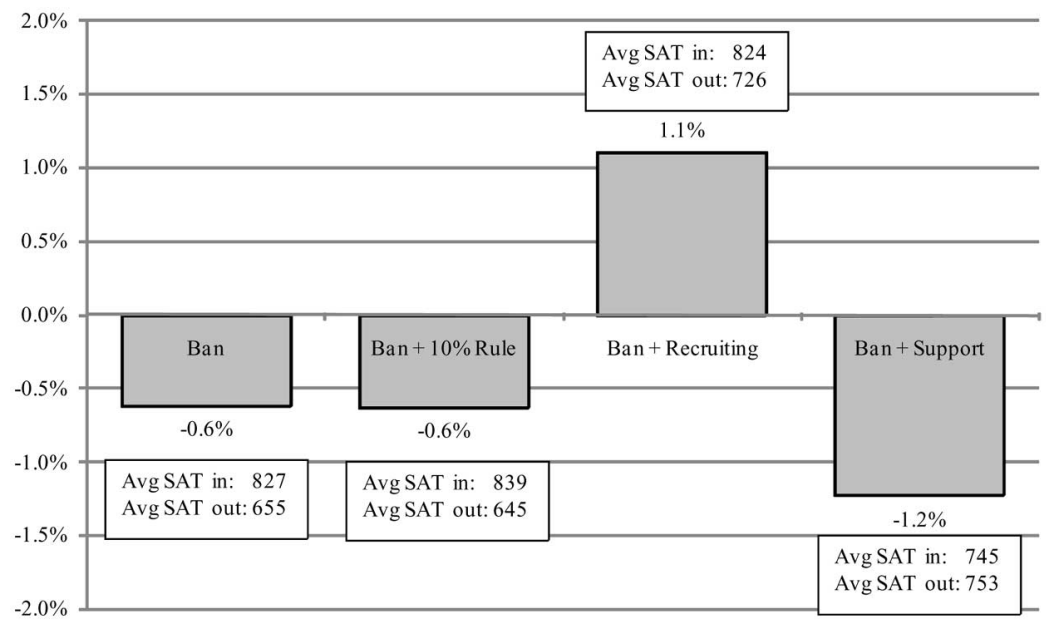

FIG. 4.-Net change in the proportion of minorities induced into 4-year college (relative to predicted baseline choices).

havior are not predicted to have particularly large effects on admission and matriculation outcomes, however. Relative to baseline behavior, the model predicts that individuals are more likely to receive zero or one admission offer and less likely to receive multiple offers. As a result, the predicted proportion of minorities enrolling in a 4-year college actually falls slightly relative to both baseline and a ban alone. As with the other affirmative action replacements, increased minority student support results in a small increase in minority representation at the most selective 4-year colleges relative to the ban alone but fails to restore that representation to baseline levels.

\section{Redistributive Effects of Banning Affirmative Action}

Figure 4 graphically summarizes the overall 4 -year college enrollment effects of the various policy experiments examined above relative to baseline choices. Replacing affirmative action with increased recruiting of minority students is the only policy change with a positive predicted effect on overall 4-year college enrollment of blacks and Hispanics. Although colleges must admit minorities with higher SAT scores following a ban than in the baseline, and the simulations confirm this, figure 4 also reveals an interesting sorting pattern by individuals induced by the policy changes

states. Because this point may apply more generally to individual application choices, additional research is needed on the effect of proximity to affordable and accessible postsecondary alternatives, particularly the extent to which these effects vary with important individual background characteristics.

Thursday Oct 082009 03:55 PM JOLE v28n1 280101 JJ 


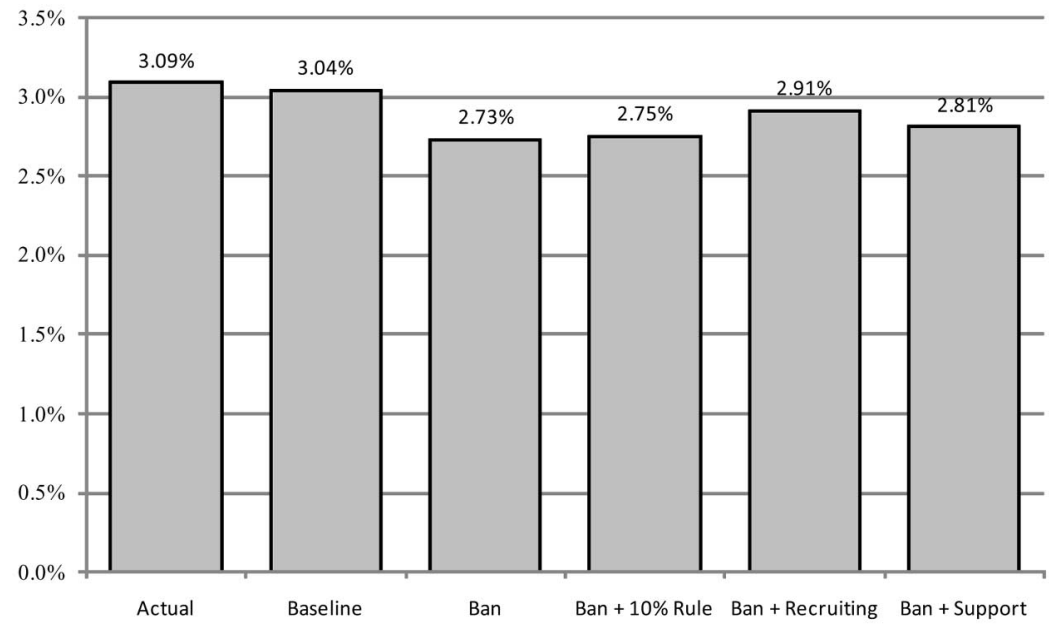

FIG. 5.-Proportion of blacks and Hispanics enrolling in most selective 4-year institutions

to make extensive margin changes. Those blacks and Hispanics who are induced to enroll by the policy changes have higher SAT scores on average than those who are induced to leave college for one of the outside options. This sorting is present in all but the final policy experiment. Assuming that more able students have a higher return to education, this sorting pattern provides some evidence that the policy changes are inducing movement among the "right" students. ${ }^{45}$

Bob Laird (2002), director of undergraduate admissions at the University of California, Berkeley, during the mid- to late 1990s, points out in The Chronicle of Higher Education that many of the minority enrollment statistics reported by the press refer to the University of California system as a whole, when in fact there is evidence of "a continuing shift of underrepresented minority students, especially African-American students, from Berkeley and UCLA to less competitive UC campuses." This response to an affirmative action ban may be viewed as particularly troublesome if there exists a substantial labor market premium associated with college quality. To address whether or not the present model predicts this type of response, figure 5 examines minority representation at those

${ }^{45}$ Taber (2001) and Carniero, Heckman, and Vytlacil (2003) provide evidence that academically more able students have a higher return to education. The results in Ashenfelter and Rouse (1998), however, are consistent with the opposite-that less able students have a higher return to education. Several other studies of this issue, Altonji and Dunn (1996) and Ashenfelter and Rouse (2000), are inconclusive about the relationship between academic ability and returns to education.

Thursday Oct 082009 03:55 PM JOLE v28n1 280101 JJ 
colleges that Barron's classifies as most competitive. ${ }^{46}$ Concerns about the redistribution effects of race-neutral admissions and the inability of replacement policies to restore preban representation of minorities at top colleges appear to be justified. The proportion of blacks and Hispanics at top institutions declines by approximately $10 \%$ (from $3.04 \%$ to $2.73 \%$ of all students) following a ban on affirmative action in college admissions. Although the model predicts that minority representation at all 4-year colleges would be increased by a program to increase minority student support, figure 5 indicates that such a program would not restore minority representation at the most selective colleges. Indeed, none of the affirmative action replacement policies are predicted to increase minority representation at top colleges to preban levels.

\section{Conclusions}

In this study, I conduct an empirical examination of the process by which individuals are matched with postsecondary alternatives. The theoretical model of application decisions by individuals developed here goes beyond treating college application as a binary decision or modeling only the most selective college to which individuals apply. This research is among the first to model an individual's choice of a portfolio of colleges by specifying college application decisions as a nonsequential search problem. All three stages of the matching process between individuals and postsecondary institutions-application, admission, and enrollment-are estimated jointly with unobserved individual heterogeneity that is permitted to influence both student and college decisions. In the present study, I use the model of individual and college behavior to address the effects of eliminating affirmative action in college admissions as well as potential replacements for affirmative action, but the model is easily applied to other policy changes that affect this matching process. For example, the model could be adapted to examine the elimination of legacy preferences in college admissions, changes in the attractiveness of 2-year colleges relative to 4-year colleges, or a variety of other changes to the demand and supply side of the market for higher education.

The structure of the model permits an examination of how exogenous changes in policy are predicted to affect individual and university choices. The results of simulated policy changes indicate that, even with a more thorough treatment of the college application process modeled here, the college application decisions of minorities do not appear to be particularly sensitive to the elimination of affirmative action in college admissions. The policy simulations also indicate that, as a result of lower probabilities of admission and fewer admission offers, overall 4-year college enrollment

\footnotetext{
${ }^{46}$ This classification refers to colleges with a median student body SAT score greater than 1,200 .
}

Thursday Oct 082009 03:55 PM JOLE v28n1 280101 JJ 
by minorities is predicted to decrease by roughly $2 \%$ following a nationwide ban on affirmative action in college admissions. Despite this fairly moderate result, race-neutral admissions are predicted to decrease minority representation at the most selective 4 -year institutions by $10.2 \%$.

The counterfactuals involving alternatives to affirmative action indicate that intensified recruiting of minorities is predicted to have the largest positive effect on black and Hispanic representation at all 4-year colleges and universities, but that none of the alternatives is predicted to restore preban levels of racial diversity at the most selective 4-year institutions. One caveat to keep in mind, however, is that there are other ways of thinking about these affirmative action replacement policies and that the policy experiment results are likely to be sensitive to the way in which these replacement policies are simulated. For example, I assume that both intensified minority recruiting and increased minority support services work through unobservable heterogeneity in the model, but these changes could just as easily be assumed to affect observable characteristics of minorities. ${ }^{47}$ Additionally, the affirmative action replacement policies are all assumed to operate through individuals' in-state colleges, but this could be further restricted to only in-state public colleges or expanded to include neighboring states that have tuition reciprocity agreements. These different modeling choices could certainly yield different results.

There are several other limitations of the analysis worth noting. First, although the theoretical model of university decision making is flexible enough to include simple financial aid award decisions, the role of financial aid is not captured in the empirical analysis. This omission is primarily due to inadequate financial aid information in NELS, but it is clearly evident from the literature that financial aid is an important determinant of postsecondary decision making, particularly for minority students who are more likely to be low-income and may also have access to inferior information about financial aid relative to their nonminority peers. Arcidiacono (2005) finds that removing race-based advantages in financial aid is associated with a larger predicted drop in college enrollment by blacks than when affirmative action is banned from college admission decisions alone, so it is possible that the estimated effect of the affirmative action ban is underestimated here. Second, in addition to financial aid, the inclusion of additional high school-level and state-level control variables may improve the model's ability to fit the data. In particular, the goodness-of-fit tests indicate that there is room for improvement regard-

\footnotetext{
${ }^{47}$ For example, increased minority support could be simulated as a precollegiate program that works by increasing minority SAT scores. This would likely have a wider effect than the way the policy change is currently simulated because higher SAT scores are valued at colleges outside of one's home state and the current simulation is restricted to affecting in-state alternatives.
}

Thursday Oct 082009 03:55 PM JOLE v28n1 280101 JJ 
ing predicting matriculation choices. It may be that including more controls for attributes of an individual's peers and high school as well as state-specific labor market and 2-year college opportunities would better capture the trade-offs faced in the matriculation stage of decision making. A final caveat is that a structural model involves a trade-off between the power to examine important policy issues not typically possible with other data/methods and the potential to misspecify the structure one places on the decision-making processes in the model. The benefit of obtaining structural parameter estimates is that they represent the true underlying preferences of the economic agents and are invariant to changes in the policy environment if the model is correctly specified. Although the model fits the observed choices in the data quite well and several important results are consistent with both reduced form and structural studies in the literature, there is always the potential for misspecification in a model as complex as the one utilized in this research.

\section{Appendix A}

\section{Dominated Strategies: Theory and Practice}

\section{Theorems}

In order to compare $S_{i a}$ with alternative strategies, I categorize all of the other strategies into four distinct groups: adjacent strategies, singleswap strategies, multiple-swap strategies, and nonadjacent strategies. If $S_{i a}=\{$ MIT, Princeton, UVa $\}$, for example, then removing the MIT application from $S_{i a}$ is an adjacent strategy to $S_{i a}$; it is adjacent to $S_{i a}$ in the sense that only one element of the strategy vector $a_{i}$ changes. Removing applications at MIT and Princeton is considered a nonadjacent strategy to $S_{i a}$; it is nonadjacent because more than one element of the vector $a_{i}$ changes. Swap strategies are a special case involving multiple changes to $a_{i}$ in which the total number of college applications in the set is maintained. In the context of the example above, dropping the application to MIT and replacing it with an application to Yale is a single-swap strategy; dropping applications to MIT and Princeton and replacing them with applications to Yale and Duke is a multiple-swap strategy. Given these definitions, the number of necessary marginal value calculations is reduced by showing that when $V\left(S_{i a}\right)$ exceeds the value of all adjacent and singleswap strategies, all nonadjacent and multiple-swap strategies to $S_{i a}$ are dominated. ${ }^{48}$ Consider three theorems. ${ }^{49}$

The first theorem says that, if an application strategy $S_{a}$ is preferred to

${ }^{48}$ The theory here is based on job search strategy research by Blau and Stern (1988).

${ }^{49}$ The proofs of the theorems below are available in Howell (2004).

Thursday Oct 082009 03:55 PM JOLE v28n1 280101 JJ 
all adjacent strategies $S_{a / j}$, then that application strategy is also preferred to all nonadjacent (nonswap) strategies $S_{a / j, k}$ (where $n_{a / j, k} \neq n_{a}$ ).

THEOREM 1. If $V\left(S_{a}\right)>V\left(S_{a / j}\right) \quad \forall j \in J$, then $V\left(S_{a}\right) \geq V\left(S_{a / j, k}\right)$ $\forall j, k \in J: j \neq k$ and $n_{a / j, k} \neq n_{a}$.

The second theorem states that, if an application strategy $S_{a}$ is preferred to all single-swap strategies $S_{a / j, k}$ (where $n_{a / j, k}=n_{a}$ ), then that application strategy is also preferred to all multiple-swap strategies $S_{a /\{b\}}$ (where $n_{a /\{b\}}=n_{a}$ and $\{b\}$ contains more than two elements).

Theorem 2. If $V\left(S_{a}\right)>V\left(S_{a / j, k}\right) \forall j, k \in J: j \neq k$ and $n_{a / j, k}=n_{a}$, then $V\left(S_{a}\right) \geq V\left(S_{a /\{b\}}\right) \forall\{b\} \subseteq J: n_{a / b\}}=n_{a}$ and $n_{b}>2$.

Theorems 1 and 2 are combined in a third theorem which states that, if an individual's application strategy is preferred to all adjacent and all single-swap strategies, then it is preferred to all nonadjacent and multipleswap strategies.

TheOREM 3. If $V\left(S_{a}\right)>V\left(S_{a / j}\right)$ and $V\left(S_{a}\right)>V\left(S_{a / j, k}\right) \forall j, k \in J: j \neq k$ and $n_{a / j, k}=n_{a}$, then $V\left(S_{a}\right)>V\left(S_{a /\{b\}}\right) \forall\{b\} \subseteq J: n_{a /\{b\}} \neq n_{a}$ and $n_{b}>2$.

The theoretical results above are instrumental in making the model tractable. Calculating the probability that $i$ applies to a particular application set $S_{i a}$ in equation (5) requires (among other things) comparing $V\left(S_{i a}\right)$ to $V\left(S_{i a}, S^{\prime}\right) \forall S^{\prime} \subseteq \Psi_{/ S_{i a}}$, where $\Psi_{/ S_{i a}}$ is the set of all possible application sets $S^{\prime}$ that exclude the colleges in $S_{i a}$ and involve the correct total number of applications reported by $i$. The theorems simplify this search over sets in $\Psi_{/ S_{i a}}$ to a search over colleges $k \in \Psi_{/ S_{i a}}$ by identifying and eliminating dominated strategies. For example, if I determine that college $m: V\left(S_{i a}, m\right)>V\left(S_{i a}, k\right), k, m \notin S_{i a}$, then the value associated with any set $S^{\prime}$ that excludes college $m$ is also less than or equal to $V\left(S_{i a}, m\right)$ and $S^{\prime}$ is identified as a dominated strategy that can be eliminated without having to compute its value.

\section{Practical Example}

Assume that there are 1,000 4-year college alternatives available. Also assume that an individual states that he applied to College no. 1 and College no. 2 and that he submitted two to four total college applications. ${ }^{50}$ This individual's observed application set, $S_{i a}^{o}$, is $\{1,2\}$, but his complete application set, $S_{i a}$, might contain up to two more colleges based on the information he revealed about the total number of college applications he submitted. Next, assume that this individual actually applied to four colleges in total. ${ }^{51}$ Because the probability associated with observing his application set involves comparing the value of different application sets

\footnotetext{
${ }^{50}$ The total number of applications submitted is reported as a categorical variable $(0,1,2-4$, or $5-8)$.

${ }^{51}$ In actuality, the total number of college applications is determined via random draw from within the reported interval.
}

Thursday Oct 082009 03:55 PM JOLE v28n1 280101 JJ 
(see eq. [5]), evaluating this probability would involve comparing the values of all sets $S_{i a}=\{1,2, j, k\} \quad \forall j, k \in(3,1,000): j \neq k$ (e.g., $V\{1,2,3,4\}$ compared to: $V\{1,2,3,5\}, \ldots, V\{1,2,3,1,000\}, V\{1,2,4,3\}$, $V\{1,2,4,5\}, \ldots, V\{1,2,4,1,000\}$, and so on). To reduce the number of comparisons and calculations that must be made, I employ the theorems to build up the set $S_{i a}$ sequentially. Namely, I consider which college, if any, this individual would add to his application set next by comparing $V\{1,2, j\}$ to $V\{1,2\}$. Once I determine, for example, that $V\{1,2,50\}>$ $V\{1,2\}$ and $V\{1,2,50\}>V\{1,2, j\} \forall j \neq 1,2,50$, then the theorems allow me to omit from consideration any application sets that do not include College no. 50 as the third college in the set. I again return to building up the set $S_{i a}$ sequentially, but now compare $V\{1,2,50, j\}$ to $V\{1,2,50\}$ $\forall j \neq 1,2,50$. Once I determine, for example, that $V\{1,2,50,600\}>$ $V\{1,2,50\}$ and $V\{1,2,50,600\}>V\{1,2,50, j\} \forall j \neq 1,2,50,600$, then I can omit from consideration any application sets that do not also include College no. 600 as the fourth college in the set. By ruling out adjacent and single-swap application strategies, I effectively eliminate nonadjacent and multiple-swap strategies from the list of potential strategies that must be evaluated.

\section{Appendix B}

\section{Estimation and Simulation Details}

The second piece of the individual likelihood contribution, which is the probability that individual $i$ follows application strategy $S_{i a}$, was specified in equation (9) in terms of the marginal value associated with applying to each college alternative. Unfortunately, this probability does not possess nice properties and is intractable to compute. ${ }^{52}$ Rather than discard the theoretical model of individual behavior developed in Section III, the kernel smoothed frequency simulator proposed by McFadden (1989) is used to approximate the probability in equation (9). Essentially, $\operatorname{Pr}\left[M V_{a / m} \gtrless 0\right]$ is approximated by $\operatorname{Pr}\left[M V_{a / m} \gtrless \eta_{i m}\right]$ for $m=j$, $k$, where $\eta$ is distributed i.i.d. extreme value with standard deviation parameter, $\tau_{\eta}$. The term $\tau_{\eta}$ is chosen so that $\eta$ has a small variance because, as $\operatorname{Var}(\eta) \rightarrow 0$, the approximation converges to the true probability in which

\footnotetext{
${ }^{52}$ Specifically, the marginal value associated with a single-swap strategy is not monotonic in $\mu_{i}$. The sign of the first derivative depends on the relative admissions probabilities and expected value of the maximum terms of the colleges being swapped. The intuition here is that, as $i$ 's unobserved taste for college increases, it is unclear whether $i$ will want to apply to fewer colleges with higher admissions probabilities or more colleges with lower admissions probabilities. This is really about the fact that two colleges in an application set may be complements for one person and substitutes for another.
}

Thursday Oct 082009 03:55 PM JOLE v28n1 280101 JJ 
I am interested. ${ }^{53}$ These assumptions allow the probability of applying to the set of colleges in $S_{i a}$ to be expressed as the product of Logit probabilities,

$$
\begin{gathered}
\operatorname{Pr}\left(i \text { applies to } S_{i a} \mid X_{i j}\right) \\
=\prod_{j \in S_{i a}} \operatorname{Pr}\left(M V_{a / j}>\eta_{i j}\right) \prod_{k \notin S_{i a}} \operatorname{Pr}\left(M V_{a / k}<\eta_{i k}\right) \\
=\prod_{j \in S_{i a}}\left[\frac{\exp \left\{M V_{a / j} / \tau \eta\right\}}{1+\exp \left\{M V_{a / j} / \tau \eta\right\}}\right] \prod_{k \notin S}\left[\frac{1}{1+\exp \left\{M V_{a / k} / \tau \eta\right\}}\right] .
\end{gathered}
$$

The likelihood contribution of individual $i$, conditional on the parameter vector $\theta$ and unobservables $\mu_{i}$ and $\xi_{i j}$, is the product of the two pieces laid out in equation (15),

$$
\begin{gathered}
L_{i}\left(\theta, \mu_{i}, \xi_{i j}\right)=\left[\frac{\exp \left\{\psi_{i m}\left(\theta, \mu_{i}, \xi_{i m}\right)\right\}}{\sum_{j \in S_{i a}^{A}} \exp \left\{\psi_{i j}\left(\theta, \mu_{i}, \xi_{i j}\right)\right\}}\right] \\
{\left[\prod_{j \in S_{i a}} \frac{\exp a_{i j} A_{i j}\left(Z_{i j} \gamma+\alpha \mu_{i}+\delta \xi_{i j}\right\}}{1+a_{i j} \exp \left\{Z_{i j} \gamma+\alpha \mu_{i}+\delta \xi_{i j}\right\}}\right]} \\
\prod_{j \in S_{i a}}\left[\frac{\exp \left\{M V_{a / j}\left(\theta, \mu_{i}, \xi_{i j}\right) / \tau_{\eta}\right\}}{1+\exp \left\{M V_{a / j}\left(\theta, \mu_{i}, \xi_{i j}\right) / \tau_{\eta}\right\}}\right] \prod_{k \notin S_{i a}}\left[\frac{1}{1+\exp \left\{M V_{a / k}\left(\theta, \mu_{i}, \xi_{i k}\right) / \tau_{\eta}\right\}}\right] .
\end{gathered}
$$

The unconditional likelihood contribution is found by integrating equation (B2) over the values of $\mu_{i}$ and $\xi_{i j}$ that satisfy theorems 1, 2, and 3,

$$
L_{i}(\theta)=\iint_{\Lambda} L_{i}(\theta, \mu, \xi) f(\mu, \xi) d \xi d \mu,
$$

where $f(\mu, \xi)$ is the joint distribution of the unobservables and

$$
\begin{gathered}
\Lambda=\left\{\mu_{i}, \xi_{i j}: V\left(S_{i a}\right) \geq V\left(S_{i a / j}\right) \text { and } V\left(S_{i a}\right) \geq V\left(S_{i a / j, k}\right)\right. \\
\left.\forall j, k \in J: j \neq k \& n_{a / j, k}=n_{a}\right\} .
\end{gathered}
$$

The likelihood contribution in equation (B3) raises several issues. First,

${ }^{53}$ Even if the variance of $\eta$ does not go to zero, this is still a very good approximation of the true probability. See Keane and Wolpin (1997), Eckstein and Wolpin (1999), and Todd and Wolpin (2006) for applications of this method.

Thursday Oct 082009 03:55 PM JOLE v28n1 280101 JJ 
the multidimensional integral cannot be computed analytically. Simulation methods are used to approximate the multidimensional integral instead. Second, the function $L_{i}\left(\theta, \mu_{i}, \xi_{i j}\right)$ is not continuous in the parameter vector $\theta$ because the number of applications in the set is discrete. This means that small changes in $\theta$ may cause discontinuous jumps in the application set, which make it impossible to employ derivative-based optimization methods in maximizing the likelihood function. Thus, in order to have derivatives that actually converge on a set of parameter estimates, the simulator chosen must also possess nice smoothness properties. An importance sampling technique solves both of these problems and does so with smaller levels of simulation error than other simulators available (Stern 1997). ${ }^{54}$

Define $g(\mu, \xi)$ to be a density with the support $\Lambda$, where $\Lambda$ is defined as above. Multiplying and dividing equation (B3) by $g(\mu, \xi)$ yields

$$
L_{i}(\theta)=\iint_{\Lambda} \frac{L_{i}(\theta, \mu, \xi) f(\mu, \xi)}{g(\mu, \xi)} g(\mu, \xi) d \xi d \mu .
$$

q20

The density $g(\cdot)$ is chosen to have the same support as $\xi, \mu$ and such that $\left[L_{i}(\theta, \mu, \xi) f(\mu, \xi)\right] / g(\mu, \xi)$ is bounded, smooth in $\theta$, and easy to evaluate given $\mu$ and $\xi$. The importance sampling simulator for $L_{i}(\theta)$ is

$$
L_{i}^{R}(\theta)=\frac{1}{R} \sum_{r=1}^{R} \frac{L_{i}\left(\theta, \mu_{i}^{r}, \xi_{i j}^{r}\right) f\left(\mu_{i}^{r}, \xi_{i j}^{r}\right)}{g\left(\mu_{i}^{r}, \xi_{i j}^{r}\right)},
$$

where $r$ indexes $R$ draws of $\mu_{i}$ and $\xi_{i j}$. The specific form of the importance sampler $g\left(\mu_{i}^{r}, \xi_{i j}^{r}\right)$ is motivated by data limitations in NELS. Please see Howell (2004) for details.

The simulated log-likelihood function that is maximized is the sum of all individuals' simulated log-likelihood contributions,

$$
\ln L^{R}(\theta)=\sum_{i=1}^{N} \ln L_{i}^{R}(\theta)
$$

where the parameters to be estimated are $\theta=\left\{\mathbf{b}, \mu_{\mu}, \sigma_{\mu}^{2}, \mu_{\xi}, \sigma_{\xi}^{2}, \tau_{\varepsilon}\right\}$. The maximum simulated likelihood estimates of $\theta$, denoted by $\theta$, are the values of those parameters that make the choice probabilities and the observed

\footnotetext{
${ }^{54}$ In order to further reduce simulation error, I use antithetic acceleration.

${ }^{55} \mathrm{MSL}$ is consistent if $R \rightarrow \infty$ as $N \rightarrow \infty$. This result should not interfere with inference based on MSL estimate of $\theta$ because Börsch-Supan and Hajivassiliou (1993) show that MSL yields precise parameter estimates in polychotomous choice models with a small, fixed number of simulations $R$. I use $R=3$ in the estimation algorithm.
}

Thursday Oct 082009 03:55 PM JOLE v28n1 280101 JJ 


\section{References}

Altonji, Joseph, and Thomas Dunn. 1996. The effects of family characteristics on the return to education. Review of Economics and Statistics 78:692-704.

Arcidiacono, Peter. 2005. Affirmative action in higher education: How do admission and financial aid rules affect future earnings? Econometrica 73, no. 5:1477-1524.

Argetsinger, Amy. 2002. Colleges lobby to move up in the polls. Washington Post, September 15.

Ashenfelter, Orley, and Cecilia Rouse. 1998. Income, schooling, and ability: Evidence from a new sample of twins. Quarterly Journal of Economics 113 , no. 1:253-84.

- 2000. Schooling, intelligence, and income in America. In Meritocracy and economic inequality, ed. Kenneth Arrow, Samuel Bowles, and Steven Durlauf. Princeton, NJ: Princeton University Press.

Avery, Christopher, Andrew Fairbanks, and Richard Zeckhauser. 2001. What worms for the early bird? Early admissions at selective colleges. Working Paper no. RWP01-049, John F. Kennedy School of Government, Harvard University.

Blau, David, and Steven N. Stern. 1988. Estimating the choice of search methods using economic necessary first order conditions. Unpublished manuscript, Department of Economics, University of Virginia.

Börsch-Supan, Axel, and Vassilis Hajivassiliou. 1993. Smooth unbiased multivariate probability simulators for maximum likelihood estimation of limited dependent variable models. Journal of Econometrics 58: $347-68$.

Bowen, William G., and Derek Bok. 1998. The shape of the river: Longterm consequences of considering race in college and university admissions. Princeton, NJ: Princeton University Press.

Breneman, David W. 1994. Liberal arts colleges: Thriving, surviving, or endangered? Washington, DC: Brookings Institution.

Brewer, Dominic J., Eric R. Eide, and Dan D. Goldhaber. 1999. An examination of the role of student race and ethnicity in higher education since 1972. Unpublished manuscript, Public Policy Institute of California, San Francisco.

Brien, Michael, Lee Lillard, and Steven N. Stern. 2006. Cohabitation, marriage, and divorce in a model of match quality. International Economic Review 47, no. 2:451-94.

Bucks, Brian. 2004. The effect of Texas' top ten percent plan on college choice. Unpublished manuscript, Green Center for the Study of Science and Society, University of Texas-Dallas.

Card, David, and Alan B. Krueger. 2004. Would the elimination of affirmative action affect highly qualified minority applicants? Evidence from

Thursday Oct 082009 03:55 PM JOLE v28n1 280101 JJ 
California and Texas. NBER Working Paper no. 10366, National Bureau of Economic Research, Cambridge, MA.

Carneiro, Pedro, James J. Heckman, and Edward Vytlacil. 2003. Understanding what instrumental variables estimate: Estimating marginal and average returns to education. Working paper, University of Chicago.

Conrad, Cecilia A., and Rhonda V. Sharpe. 1996. The impact of the California civil rights initiative. Review of Black Political Economy 25, no. 1:13-47.

Dale, Stacy B., and Alan B. Krueger. 2002. Estimating the payoff to attending a more selective college: An application of selection on observables and unobservables. Quarterly Journal of Economics 117: 1491-1527.

Duffy, Elizabeth A., and Idana Goldberg. 1998. Crafting a class: College admissions and financial aid, 1955-1994. Princeton, NJ: Princeton University Press.

Eckstein, Zvi, and Kenneth I. Wolpin. 1999. Why youths drop out of high school: The impact of preferences, opportunities and abilities. Econometrica 67, no. 6:1295-1340.

Ehrenberg, Ronald G., and Daniel R. Sherman. 1984. Optimal financial aid policies for a selective university. Journal of Human Resources 19, no. 2:202-30.

Garvin, David A. 1980. The economics of university behavior. New York: Academic Press.

Gilleskie, Donna B. 1998. A dynamic stochastic model of medical care use and work absence. Econometrica 66, no. 1:1-45.

Goeree, Michelle S. 2008. Limited information and advertising in the US personal computer industry. Econometrica 76, no. 5:1017-74.

Heckman, James J., Lance Lochner, and Christopher Taber. 1998. Generalequilibrium treatment effects: A study of tuition policy. AEA Papers and Proceedings 88, no. 2:381-86.

Hotz, V. Joseph, and Robert A. Miller. 1993. Conditional choice probabilities and the estimation of dynamic models. Review of Economic Studies 60, no. 3:497-529.

Howell, Cameron, and Sarah E. Turner. 2004. Legacies in black and white: The racial composition of the legacy pool. Research in Higher Education 45 , no. 4:325-51.

Howell, Jessica S. 2004. A structural equilibrium model of the market for higher education: Assessing the impact of eliminating affirmative action. PhD diss., Department of Economics, University of Virginia.

Huber, P. J. 1967. The behavior of maximum likelihood estimates under non-standard conditions. Proceedings of the Fifth Berkeley Symposium on Mathematical Statistics and Probability 1:221-33.

James, Estelle. 1990. Decision processes and priorities in higher education.

Thursday Oct 082009 03:55 PM JOLE v28n1 280101 JJ 
In The economics of American universities, ed. S. Hoenack and E. Collins. Albany: State University of New York Press.

Kain, John F., and Daniel M. O'Brien. 2003. Hopwood and the top 10 percent law: How they have affected the college enrollment decisions of Texas high school graduates. Unpublished manuscript, Green Center for the Study of Science and Society, University of Texas-Dallas.

Kane, Thomas J. 1998. Racial and ethnic preferences in college admissions. In The black-white test score gap, ed. C. Jencks and M. Phillips. Washington, DC: Brookings Institution Press.

Keane, Michael P. 2006. Structural vs. atheoretic approaches to econometrics. Keynote address, Duke University Conference on Structural Models in Labor, Aging, and Health, September 17-19.

Keane, Michael P., and Kenneth I. Wolpin. 1997. Career decisions of young men. Journal of Political Economy 105:473-522.

Kreps, D., and R. Wilson. 1982. Reputation and imperfect information. Journal of Economic Theory 27:253-79.

Laird, Bob. 2002. Bending admissions to political ends. Chronicle of Higher Education, May 17.

Light, Audrey, and Wayne Strayer. 2002. From Bakke to Hopwood: Does race affect college attendance and completion? Review of Economics and Statistics 84, no. 1:34-44.

Long, Mark. 2004. College applications and the effect of affirmative action. Journal of Econometrics 121:319-42.

McFadden, Daniel. 1978. Modelling the choice of residential location. In Spatial interaction theory and residential location, ed. A. Karlquist et al. Amsterdam: North-Holland.

- 1989. A method of simulated moments for estimation of discrete response models without numerical integration. Econometrica 57, no. 5:995-1026.

Mahoney, John. 2002. The lure of early admissions. Currents (April). Council for Advancement and Support of Education, Washington, DC. Manski, Charles F., and David A. Wise. 1983. College choice in America. Cambridge, MA: Harvard University Press.

Mathews, Jay. 2000. Admissions obsession. Washington Post, November 7.

Milgrom, Paul, and J. Roberts. 1986. Prices and advertising signals of product quality. Journal of Political Economy 94, no. 4:796-821.

Miller, Leonard S. 1981. College admissions and financial aid policies as revealed by institutional practices. Economic Inquiry 19, no. 1:117-31.

Monks, James, and Ronald G. Ehrenberg. 1999. U.S. News \& World Report's college rankings: Why do they matter? Change 31, no. 6: 42-51.

NCES (National Center for Education Statistics), U.S. Department of Education. Various years. Common core of data: Public elementary/

Thursday Oct 082009 03:55 PM JOLE v28n1 280101 JJ 
secondary school universe survey. Downloaded from http://nces.ed.gov/ $\mathrm{ccd} /$ psuinfo.asp.

NCES (National Center for Education Statistics), U.S. Department of Education. 1996. National education longitudinal study: 1988-1994. Restricted Use CD-ROM. Washington, DC: U.S. Department of Education.

Radner, Roy, and Leonard S. Miller. 1975. Demand and supply in U.S. higher education. New York: McGraw-Hill.

Stern, Steven N. 1997. Simulation-based estimation. Journal of Economic Literature 35, no. 4:2006-39.

Taber, Christopher. 2001. The rising college premium in the eighties: Return to college or return to unobserved ability? Review of Economics Studies 68, no. 3:665-91.

Tienda, Marta, Kevin T. Leicht, Teresa Sullivan, Michael Maltese, and Kim Lloyd. 2003. Closing the gap? Admissions and enrollments at the Texas public flagships before and after affirmative action. Working Paper no. 2003-01, Office of Population Research, Princeton University.

Todd, Petra, and Kenneth I. Wolpin. 2006. Assessing the impact of a school subsidy program in Mexico: Using experimental data to validate a dynamic behavioral model of child schooling and fertility. American Economic Review 96, no. 5:1384-1417.

White, Hal. 1980. A heteroskedasticity-consistent covariance matrix estimator and a direct test for heteroskedasticity. Econometrica 48, no. 4: 817-38.

Williams, Stephanie. 2001. Early admissions madness. Time/the Princeton Review's the best college for you 2001.

Winston, Gordon C. 1997. Why can't a college be more like a firm? Working paper, Williams Project on the Economics of Education, Williams College.

Thursday Oct 082009 03:55 PM JOLE v28n1 280101 JJ 


\section{QUERIES TO THE AUTHOR}

1 Please check the url in note 2; it doesn't work for me.

2 Press style discourages the use of italics for emphasis. If there are italics that should be restored to preserve your meaning, please indicate those.

3 Please give the page number for the quotation from Heckman et al. 1998.

4 "The utility" has been added here because it is this journal's style that a sentence should not begin with a mathematical expression or symbol. Feel free to substitute other words or to recast the sentence if you wish.

5 Please check throughout that the math has been set correctly.

6 Fractions in this line and in note 15 have been unstacked because the run of text does not accommodate stacked fractions. Please check that this has been done correctly.

7 In note 16: JOLE style is to write out most abbreviations the first time they occur: correct to expand i.i.d. as "independently and identically distributed"? If not, please provide the correct wording. Also, please write out "EV" this first time it appears.

8 "The terms" has been added here because it is this journal's style that a sentence should not begin with a mathematical expression or symbol. Feel free to substitute other words or to recast the sentence if you wish.

9 Notes 17 and 18 were combined following Press style, which avoids using more than one note reference at a single location.

10 "Iff" expanded here per JOLE style: "if and only if" correct?

Thursday Oct 082009 03:55 PM JOLE v28n1 280101 JJ 
11 "The amount" has been added here because it is this journal's style that a sentence should not begin with a mathematical expression or symbol. Feel free to substitute other words or to recast the sentence if you wish.

12 Notes 27 and 28 were combined following Press style, which avoids using more than one note reference at a single location.

13 "Admissions Decision" is the only subheading on this level in this section. Press style calls for at least two subheads at every level. Would you like to add another subheading in this section? Or delete this one?

14 In table 4, what does "Mfx" stand for?

15 Fractions in this line and below have been unstacked because the run of text does not accommodate stacked fractions. Please check that this has been done correctly.

16 Please check the sentence beginning "Although colleges must admit." The word "than" implies a comparison, but it's not clear what is being compared. Is the meaning that colleges must admit more minorities with higher SAT scores following a ban than in the baseline? Please advise.

17 Please give the page number for the quotation from Laird 2002.

18 "The term" has been added here because it is this journal's style that a sentence should not begin with a mathematical expression or symbol. Feel free to substitute other words or to recast the sentence if you wish.

19 Fractions in equations B1 and B2 have been unstacked because fractions inside fraction set too small to read. Please check that this has been done correctly.

20 A fraction in this line has been unstacked because the run of text does not accommodate stacked fractions. Please check that this has been done correctly.

Thursday Oct 082009 03:55 PM JOLE v28n1 280101 JJ 
21 In note 55, please write out "MSL."

22 For Laird 2002, please give the page numbers of the article.

23 For Mahoney 2002, please give the page numbers of the article.

24 For Williams 2001, please give the publisher's name and city of publication. Or, if a Web page, please give the URL. 